University of Louisville

ThinkIR: The University of Louisville's Institutional Repository

Electronic Theses and Dissertations

$12-2011$

\title{
Hazardous risk management survey and inland water survey.
}

Ayodeji Abimbola Lasisi

University of Louisville

Follow this and additional works at: https://ir.library.louisville.edu/etd

\section{Recommended Citation}

Lasisi, Ayodeji Abimbola, "Hazardous risk management survey and inland water survey." (2011). Electronic Theses and Dissertations. Paper 794.

https://doi.org/10.18297/etd/794

This Master's Thesis is brought to you for free and open access by ThinkIR: The University of Louisville's Institutional Repository. It has been accepted for inclusion in Electronic Theses and Dissertations by an authorized administrator of ThinkIR: The University of Louisville's Institutional Repository. This title appears here courtesy of the author, who has retained all other copyrights. For more information, please contact thinkir@louisville.edu. 


\title{
HAZARDOUS RISK MANAGEMENT SURVEY And \\ INLAND WATERWAY SURVEY
}

\author{
by \\ Ayodeji Abimbola Lasisi \\ B.S., University of Kentucky 2008
}

\author{
A thesis \\ Submitted to the Faculty of the \\ University of Louisville \\ J.B. Speed School of Engineering \\ For the Professional Degree \\ MASTER OF SCIENCE \\ Department of Engineering \\ December 2011
}




\section{HAZARDOUS MATERIAL HIGHWAY SHIPMENTS SURVEY \\ And \\ INLAND WATERWAY SURVEY}
Submitted by:
Ayodeji Lasisi
A Thesis Approved on
$12|02| 2011$
(Date)

by the Following Reading Committee:

Dr. Bai Lihui, Thesis Director

Dr. Sun Zhihưं

Dr. Suraj Alexander 


\section{ABSTRACT \\ HAZARDOUS MATERIAL HIGHWAY SHIPMENTS SURVEY \\ And \\ INLAND WATERWAY SURVEY \\ Ayodeji A. Lasisi}

December 2, 2011

The trucking industry is the largest freight sector, making up about 70 percent of all domestic shipment in the United States and contributes greatly the American economy. About 10 billion tons of goods are shipped annually and of that, about 800,000 shipments of hazardous materials are transported in the United States each day by trucks, resulting in 300 million annual shipments (Federal Motor Carrier Security Administration). These hazardous materials (HazMat) range from relatively harmless products, such as hair spray and perfumes, to bulk shipments of gasoline by highway cargo tanks, to transportation of poisonous, explosive, and radioactive materials. The complexity of this commodity makes them of particular interest, especially to carriers, shippers, consignees, emergency responders, and government officials. However, at both the national and state levels, the transport of HazMat shipments has not been analyzed to the degree necessary to completely understand the operational logistics. To assist strategic planning on the development and expansion for highway infrastructure and to mitigate security risk due to HazMat shipment, it is necessary to understand their shipment/flow characteristic, and more broadly, the current awareness and preparedness 
of shippers and carries of risk mitigation. Therefore, more research is necessary to help federal and local government to make efficient regulations regarding risk mitigation of HazMat highway shipments.

The objective of this project is to understand the risk involved with HazMat shipment and the mitigation strategies/tools used in an effort to lessen the impact of HazMat-caused incidents on people, property and environment through actions taken before a disaster strikes. To accomplish this objective, a survey questionnaire was developed and distributed to HazMat shippers/carriers. The questionnaire mainly consists of three parts: part 1, background information of survey participants including company name, size, and location; part 2, commodity flow characteristics including HazMat type, shipping tonnage, and shipping mileage, etc.; and part 3: the state and future of risk mitigation including current precautionary measures and technologies, and future plans on strengthening security, etc.

Inland waterway (IWW) is another important mode of transportation in the U.S. The inland waterways networks consist of nearly 12,000 navigable miles which makes it vast in geographical area and ability to carry high tonnages of goods (U.S Army Corps of Engineers, 2005). The direct access to large ports makes it a very beneficial for carriers using this mode of shipment. The inland waterways accounts for over 624 million tons of freight annually and create tremendous cost savings for U.S agriculture sector. It is also has a vital connection in energy production in the U.S resulting in low energy cost. This makes it a crucial economy contributor; making up $14 \%$ of our intercity freight and is valued nearly $\$ 70$ billion (National Waterways Foundation, 2008). It is a logical mode for transporting several commodities due to its relative low cost compare to other modes 
of transportation and more environmentally friendly option. Despite these benefits inland waterway for shipment remains under-utilized and many of the existing infrastructures are nearing their designed life span.

The objectives our research are: 1 . To understand the factors that manufacturers consider before choosing what mode of transportation is appropriate for their commodity; 2. To propose an incentive that will either encourage participants who are currently using inland waterways to increase the volume transported via inland waterway or stimulate those who are not currently using to consider shipping via inland waterway. A survey questionnaire was designed and distributed to manufacturers. Data collected from the survey was analyzed and presented the subsequent chapters.

This document focuses on the two areas discussed earlier; First, Risk Management of Hazardous Material (Chapter 1) and second, Identify factors that can help boost the use of inland waterway shipment (Chapter 7). The goal is to observe data collected from surveys and propose recommendations that can be used to improve both area of focus at the end of this research. 


\section{ACKNOWLEDGMENTS}

I would never have been able to finish my Thesis without the guidance of my Advisor, help from friends, and support from my family and wife and my Kids.

I have sincere gratitude for my supervisor Dr. Bai Lihui, for her constant support during this research period. Her guidance certainly helped me stay focus on my research study. I also like to thank my second supervisor Dr. Sun Zhihui, for all your time and recommendations regarding my work; all which greatly contributed to the success of this research. I feel very privileged to have worked closely with you both.

I will also like to thanks the staff of the Kentucky Transportation Center for giving me this opportunity to work on this research, especially Mr. Doug Kreis, Ms. Sarah McCormack, and Mr. Patrick Bigger. I would like to thank Ashley Suazo who helped me with survey distribution and collections.

I would also like to thank my parents, three sisters, and brother. They were always supporting me and encouraging me with their best wishes.

Finally, I would like to thank my wife, China Lasisi, for your loving, support, encouragement, and patience during the final stages of my Master. You are so appreciated.

Thank you 


\section{TABLE OF CONTENTS}

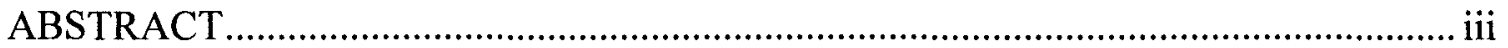

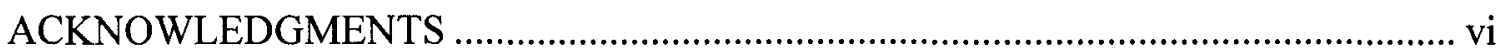

TABLE OF CONTENTS.................................................................................... vii

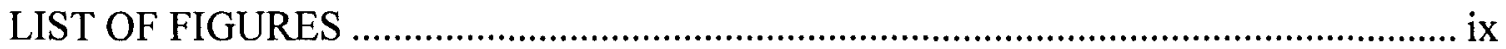

LIST OF TABLES

\section{Part I Hazmat Highway Shipment survey}

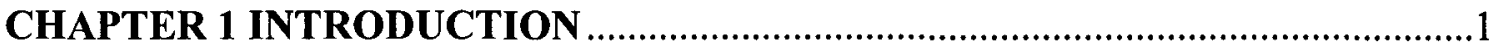

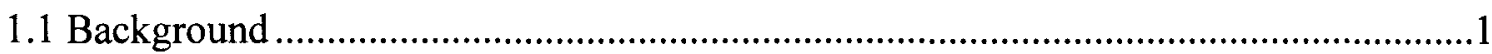

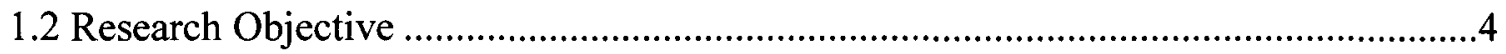

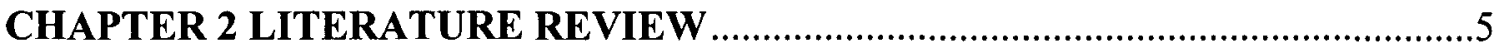

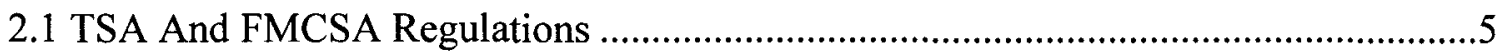

2.3 HazMat Classification And Recommended Actions ................................................6

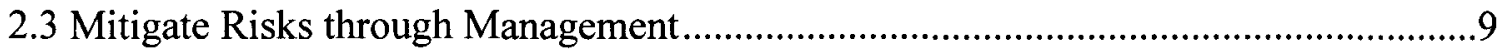

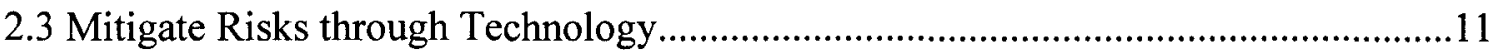

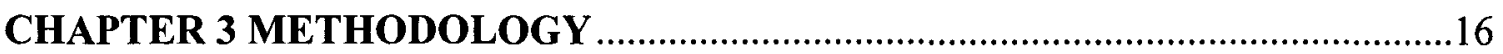

3.1 Risk Exposure Diagram In Hazmat Transportation.............................................16

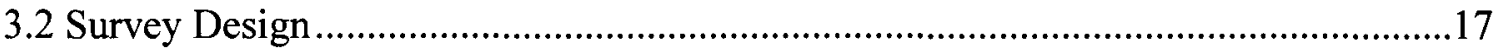

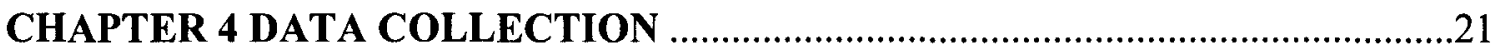

CHAPTER 5SURVEY RESULT AND DATA ANALYSIS .................................23

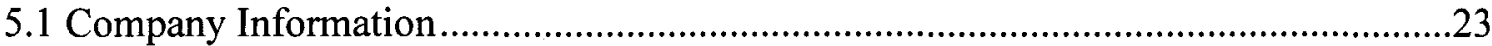

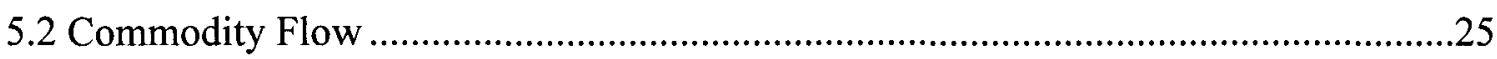

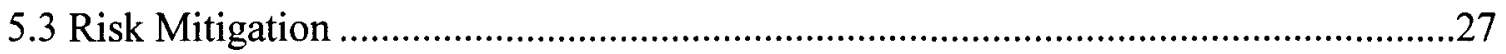

CHAPTER 6 CONCLUSIONS AND RECOMMENDATIONS ................................38 
Part II Inland Waterway Survey

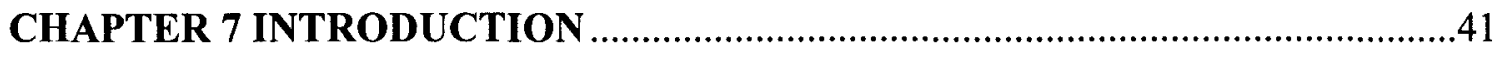

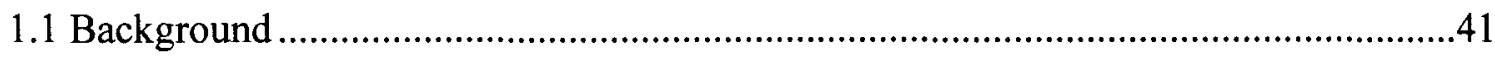

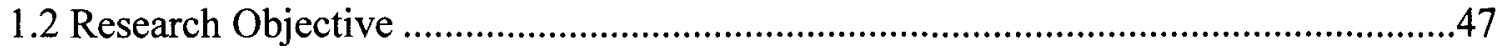

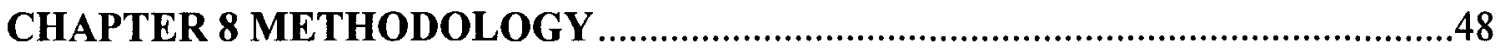

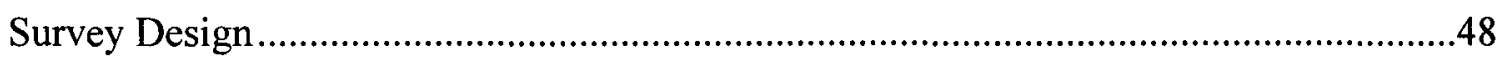

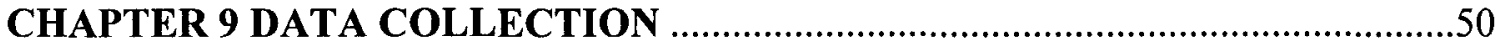

CHAPTER 10 SURVEY RESULT AND DATA ANALYSIS ……….....................52

4.1 Company Information..........................................................................................52

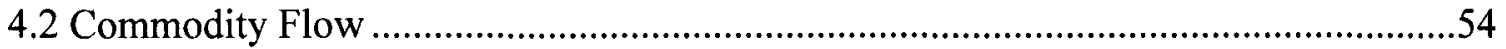

CHAPTER 11 CONCLUSIONS AND RECOMMENDATIONS ………………….....66

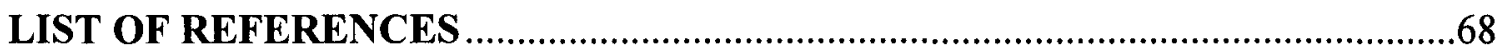

APPENDIX A Carrier and Manufacture Survey ………………………………….......70

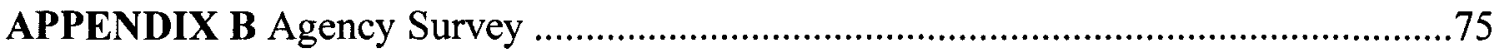

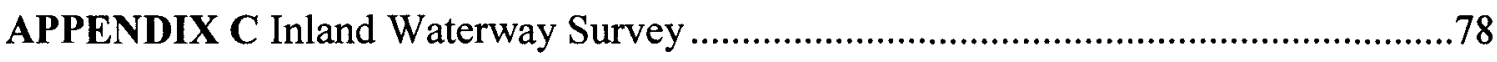

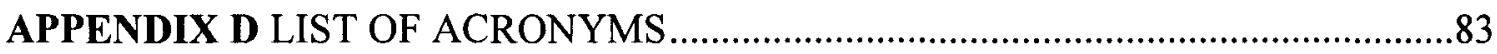

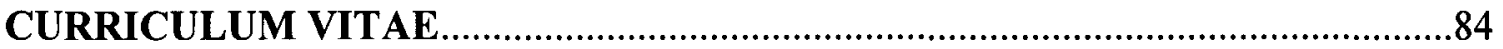




\section{LIST OF FIGURES}

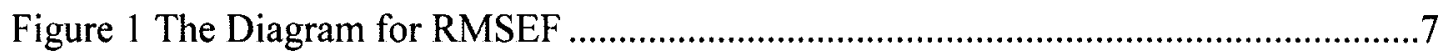

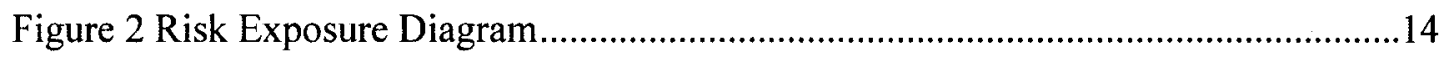

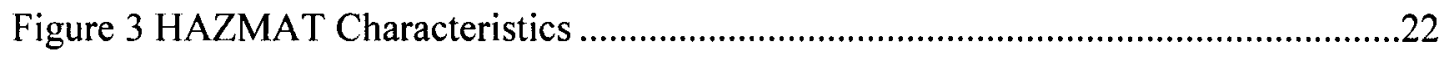

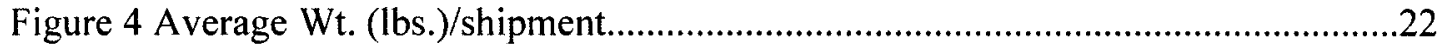

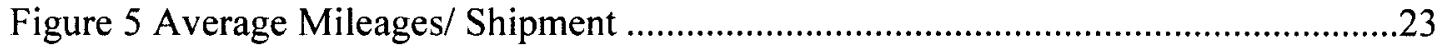

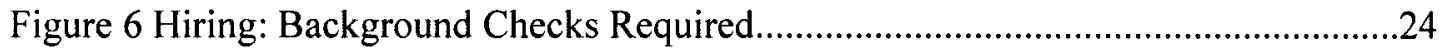

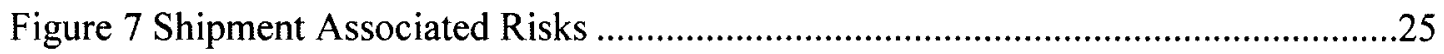

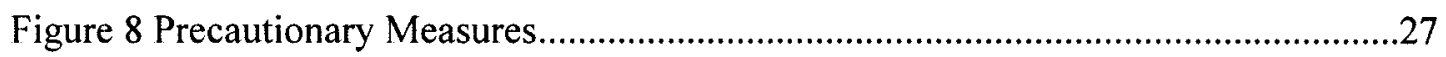

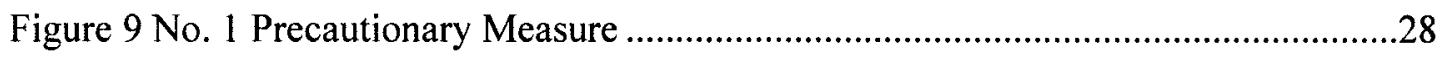

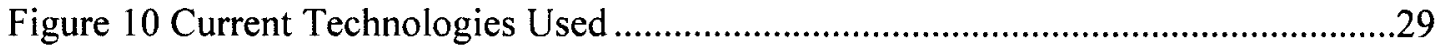

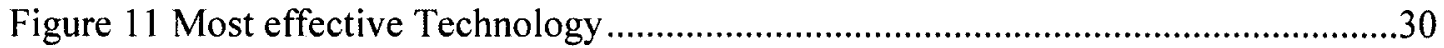

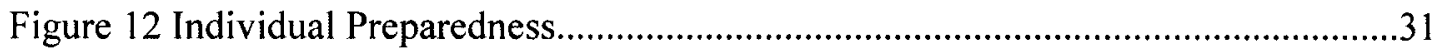

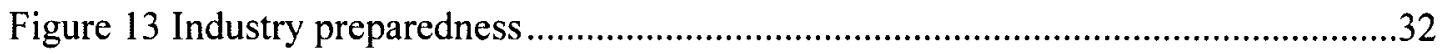

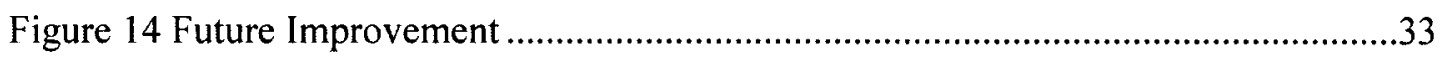

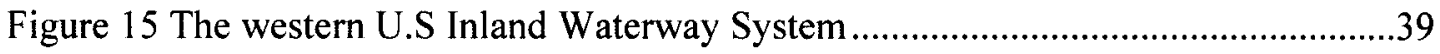

Figure 16 The eastern U.S Inland Waterways System ..................................................39

Figure 17 Total U.S Waterways Traffic by Commodity, 2003 .....................................40

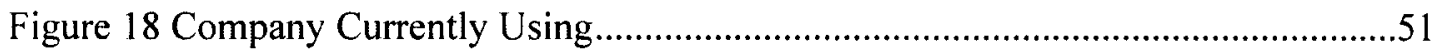

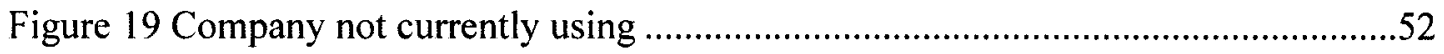

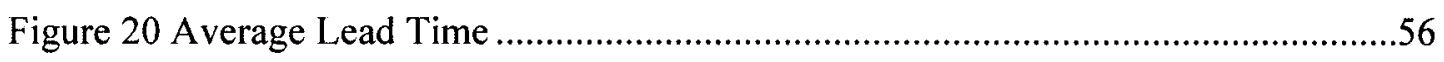

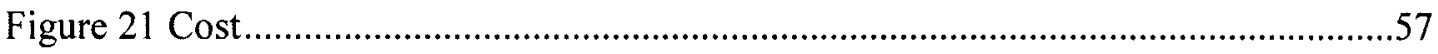

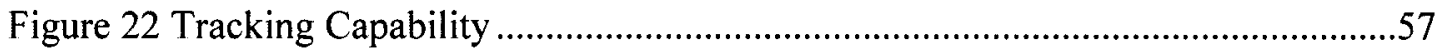

Figure 23 Reliability/Predictability of lead time .........................................................58

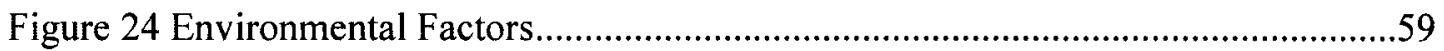

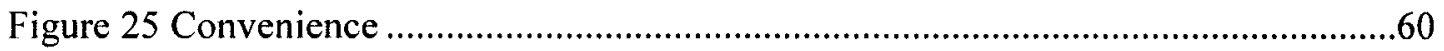




\section{LIST OF TABLES}

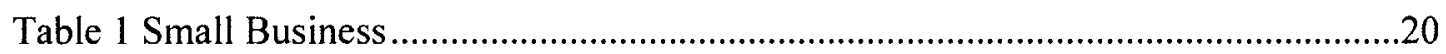

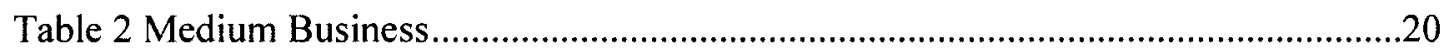

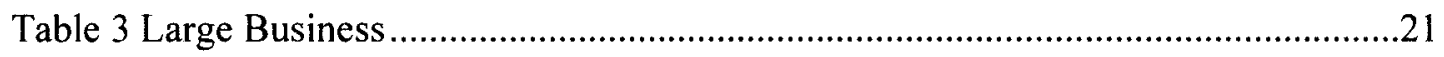

Table 4 Company that currently ship via Inland waterways............................................48

Table 5 Company that do not currently ship via Inland waterways ................................49

Table 6 Company that currently ship via Inland waterways cost factor...........................54

Table 7 Company that do currently ship via Inland waterways cost factor........................54 


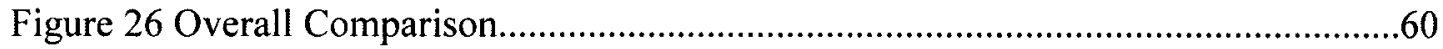




\section{CHAPTER 1 INTRODUCTION}

\section{HAZARDOUS RISK MANAGEMENT SURVEY}

\subsection{BACKGROUND}

The trucking industry is the largest freight sector, making up about 70 percent of all domestic shipment in the United States (Federal Motor Carrier Safety Administration (FMCSA) 2003). Particularly, according to FMCSA (2003) about 10 billion tons of goods are shipped annually and of that, approximately 800,000 shipments of hazardous materials (HazMat) are transported in the United States each day by trucks, resulting in roughly 300 million annual shipments. These hazardous materials range from relatively harmless products, such as hair spray and perfumes, to bulk shipments of gasoline by highway cargo tanks, to transportation of poisonous, explosive, and radioactive materials. The complexity of this commodity makes them of particular interest, especially to carriers, shippers, consignees, emergency responders, and government officials. Hazardous materials play an important role in many industries as well as our society's daily functions due to the wide range of their applications. For instance, crude oil which is very flammable is a commodity that has several applications after refining. As another example, ammonia, a chemical that can be very toxic, is an important product for making fertilizers that provides increased yields of crops. Thus, there is no doubt that the economic impact of hazardous materials is significant. 
On the other hand, due to the inherited safety and security concerns of HazMat, precautions need to be taken on handling and transporting HazMat. The mishandling of HazMat can pose great danger to not just humans, but also our environment. Hazardous materials can occur as solids, liquids and/or gases that can cause death, long-lasting health effects, serious injuries, and damage to our home and environment. Thus, the transportation, storage and disposal of HazMat require good safety precautionary measures in order to mitigate the risk associated with it. The need for continuous improvement and awareness is important for the protection of human life and our environment. Also, the property damage caused by the mishandling of a HazMat can cost stakeholder dearly. The commitment to safety should be $100 \%$ by every party involved in the shipment of HazMat.

Despite increasing efforts on preventative programs for safer transportation of hazardous materials, HazMat incidents have jumped up 20 percent in 2010 compared to 2000 (Department of Transportation, 2011). These incidents have caused property damage in millions of dollars per year, invaluable human death, and irreparable long-term damage on environment. Although, the relative amount of incidents that occurs in HazMat transportation is low compared to the entire motor transportation industry, its consequences can be more devastating and its economic effect can very negative to stakeholders. Some of the accidents occur as a result of human error and lack of good safety policies. The absence of good and effective safety policies can result in increased accident, insurance premiums, and fines, among many others. This suggests that there is plenty of room for improving safety and security for this sector of transportation. More importantly, there needs to be a cooperative effort amongst all stakeholders 
(manufacturers, carriers, shippers, and federal agencies) for a continuous improvement in safety regulations. Security is another concern associated with HazMat transportation. The 911 Attack in the United State of America on September 11, 2001 gave the U.S. as well as the international community a grim reminder that extraordinary and creative measures are deserved to protect civilians around the globe. The 911 commission, appointed by President George W. Bush after the 911 attack, concluded that the main reason that the attack occurred so easily was due to lack of imagination (9-11 commission, 2011).

In fact, it does not take much imagination to think of terrorist groups using fuels or other HazMat in mobile vehicles to attack targets. In recent history, for example, on October 21 of 2006, a car bomb carrying $12120 \mathrm{~mm}$ mortar shells and two 100-pound chlorine tanks detonated, wounding three Iraqi policemen and a civilian in Ramadi Moreover, on February 21 of 2007, a pickup truck carrying chlorine gas cylinders exploded in Baghdad, killing at least five people and hospitalizing over 50 (MSNBC, 2007). There is no hesitation that many HazMat materials pose security threats, and the Department of Transportation (DOT) and Transportation Security Administration (TSA) recognize this threat. They recommend that the security of the sector of HazMat transportation requires continuous monitoring and improvement.

In order to effectively monitor and improve the safety and security of HazMat transportation, DOT and TSA mandate many regulations, protocols and standards that all HazMat carriers must comply with. Thus, it is important to engage HazMat carriers and even HazMat drivers in the process of improving and monitoring the safety and security of HazMat transportation. Nevertheless, complying with these regulations often conflict 
with the financial objective of maximizing net profits, i.e., minimizing costs. This is because of the extra resources, such as time, personnel, equipment, required by these regulations and/or protocols. On the other hand, about $98 \%$ of the trucking industry comprises of small businesses (Wisconsin motor carrier association (WMCA) 2011), and it is extremely difficult for them to fully commit to prioritizing safety and security compliances over cost effectiveness, especially during an economic down turn.

\subsection{RESEARCH OBJECTIVE}

The Objective of this survey is three-folded. First, we would like to gain the knowledge on the management and operational tools that are currently used by HazMat carriers to ensure the safety of their drivers as well the HazMat commodity they are transporting. Second, we would like to gain the knowledge on the effectiveness of existing and potential measures for reducing risks associated with HazMat transportation. Third, we would like to understand how HazMat carriers view the current state of security and preparedness of their company and the industry as a whole in case of an emergency situation. This will help to identify improvement areas for a more secured delivery of HazMat. 


\section{CHAPTER 2 LITERATURE REVIEW}

The amount of research studies that have dealt with the management of hazardous material in terms of our objective is sparse. Therefore, in other to acquire some useful information, different disciplines will be studied. The literature is divided into four different sections. First, Federal agencies and what role they play in the enforcement of regulations. Second is the classification of HazMat. Third is some of management frameworks that already exist for mitigating risk associated with HazMat and lastly, technologies can be in used to mitigate risk.

\subsection{TSA AND FMCSA REGULATIONS}

On November 25, 2002, one year after the 911 attack, the U.S. Department of Homeland security (DHS), along with the Transportation Security Administration (TSA) was created in response to the September 11 attack. The Transportation Security Administration main purpose is protect the nation's transportation system to ensure the safety of all people migrating across the U.S. in respective of what transportation mode they choose. TSA has taken several precaution measures, such as federalization and improvement in passengers and cargo screening at airport and security regulations for other sectors of transportation. TSA is able to achieve their goals by imagining different scenario of potential attacks and coming up with mitigation approach. The responsibility is shared with the Federal Motor Carrier Safety Administration (FMCSA), whose primary mission is improving the safety of commercial motor vehicles and truck drivers by enacting and enforcing safety regulations. 
As mentioned previously, HazMat transportation has been recognized by TSA as a source of security and public safety threat. Thus, they have developed frameworks to mitigate the safety and security risks associated with transporting HazMat, and have enforced several regulations for any party involved with HazMat shipment to comply with. Particularly, FMCSA introduced a safety permit for hazardous materials on January 1, 2005. Radioactive substances, explosive, materials poisonous by inhalation and liquefied gases with methane content of $85 \%$ or more, are among the restricted highly hazardous materials included in the program (Transportation Security Administration, 2005). For Transporters to carry these hazardous materials on America's highways, it is mandatory that they obtain safety permits. Furthermore, the requirements to acquire a safety permit include the following: (1) an adequate safety ranking that requires the company to be among the top $70 \%$ in terms of low accident rate within the trucking industry, (2) a total out-of service (OOS) rate below 30\%; (3) a standard security program with a security plan; (4) a communication plan; (5) an accreditation that all HazMat employees have undergone adequate security training (Federal Motor Carrier Security Administration, 2011)

These requirements lay the foundation for further regulations and protocols aiming to reduce the risks in transporting HazMat. The latter often varies based on the nature of a particular HazMat. Below is an overview of classification of hazardous materials.

\subsection{HAZMAT CLASSIFICATION AND RECOMMENDED ACTIONS}

There are 9 different classifications for HazMat, depending their physical property and natural characteristics. These classifications are as follows: 
- Class 1: Explosives

- $\quad$ Class 2: Flammable Gas

- $\quad$ Class 3: Flammable Liquids

- $\quad$ Class 4: Flammable Solids

- Class 5: Oxidizing Agents and Organic Peroxides

- $\quad$ Class 6: Toxic and Infectious Substances

- $\quad$ Class 7: Radioactive substances

- $\quad$ Class 8: Corrosive Substances

- Class 9: Miscellaneous

The requirements and regulations for handling each HazMat differ depending on their classifications.

TSA developed voluntary security practices, which they referred to as Security Action Items (SAIs) that will increase the security of certain highway security-sensitive materials transported by motor vehicle. Highway Security-Sensitive Materials (HSSM) is a material that has the ability to cause a significant risk to national security while in transit due to terrorism. The SAIs consists of 23 guidelines and is divided into four different groups: General Security, Personnel Security, Unauthorized Access and Enroute Security.

Also, TSA divides the HSSM into two categories: Tier 1 HSSM and Tier 2 HSSM. A HSSM are mostly explosives, non- flammable gas, flammable liquid, toxic gas, radioactive substances and corrosive substances. Extra precaution is recommended when 
transporting Tier 1 HSSM, because they have a potential of causing a higher level of damage to human life, environment, disrupt transportation and economy.

Once the class of a HazMat is identified, HazMat carriers or even drivers can seek recommended actions for the particular class of HazMat. Below is the list of recommended actions, where actions 1 through 16 apply to both tiers and 17 through 23 apply to Tier 2 only.

\section{General Security}

1. Security Assessment and Security Plan Requirement

2. Awareness of Industry Security Practices

3. Inventory Control Process

4. Business and Security Critical Information

\section{Personnel Security:}

5. Possession of a Valid Commercial Driver's License-Hazardous Materials Endorsement

6. Background checks for highway transportation sector employees other than motor vehicle drives with valid CDL with hazardous materials endorsement

7. Security Awareness Training for Employees

Unauthorized Access:

8. Access Control Systems for Drivers (in addition to CDL)

9. Access Control System for Facilities Incidental to Transport

En-route Security: 
10. Establish communications Plan

11. Establish Appropriate Vehicle Security Program

12. Establish Appropriate Cargo Security Program to Prevent Theft or Sabotage of Cargo Containers

13. Implement a Seal/Lock Control Program to prevent Theft of Cargo

14. Highway Alert Level Protocols

15. Establish Inspection Policy and Procedures

16. Establish Reporting Policy and Procedures

17. Shipment Pre-Planning, Advance Notice of Arrival and Receipt Confirmation Procedures with Receiving Facility

18. Preplanning Routes

19. Security for Trips Exceeding Driving Time under the Hours of Service of Drivers Regulation

20. Dedicated Truck

21. Tractor Activation Capability

22. Panic Button Capability

23. Tractor and Trailer Tracking Systems

\subsection{MITIGATE RISKS THROUGH MANAGEMENT}

In January 2002, a Risk Management Self-Evaluation Framework (RMSEF) was developed by DOT and TSA as a voluntary tool to help evaluate and manage risk in a proactive manner because there is always opportunity for improvement. The RMSEF is governed by a set of principles that are critical for successfully managing risk. They are outlined below: 
1. Obtaining commitment to reducing security risks on the path of both managers and workers.

2. Promoting a "risk reduction culture with a security focus" in day-to-day operations.

3. Partnering with all parties involved in securing the hazardous materials transportation chain.

4. Prioritizing security risks so that resources can be allocated effectively.

5. Taking action to reduce the security risks that have been identified.

6. Striving for continuous improvement.

7. Communicating with all parties to ensure each knows its role and is aware of relevant security risk information.

Note that the above RMSEF's is a process with seven steps. The framework gives stakeholders the opportunity to customize each step to fit their organization. The diagram 
in Figure 1 illustrates the interrelations among the seven steps in the RMSEF.

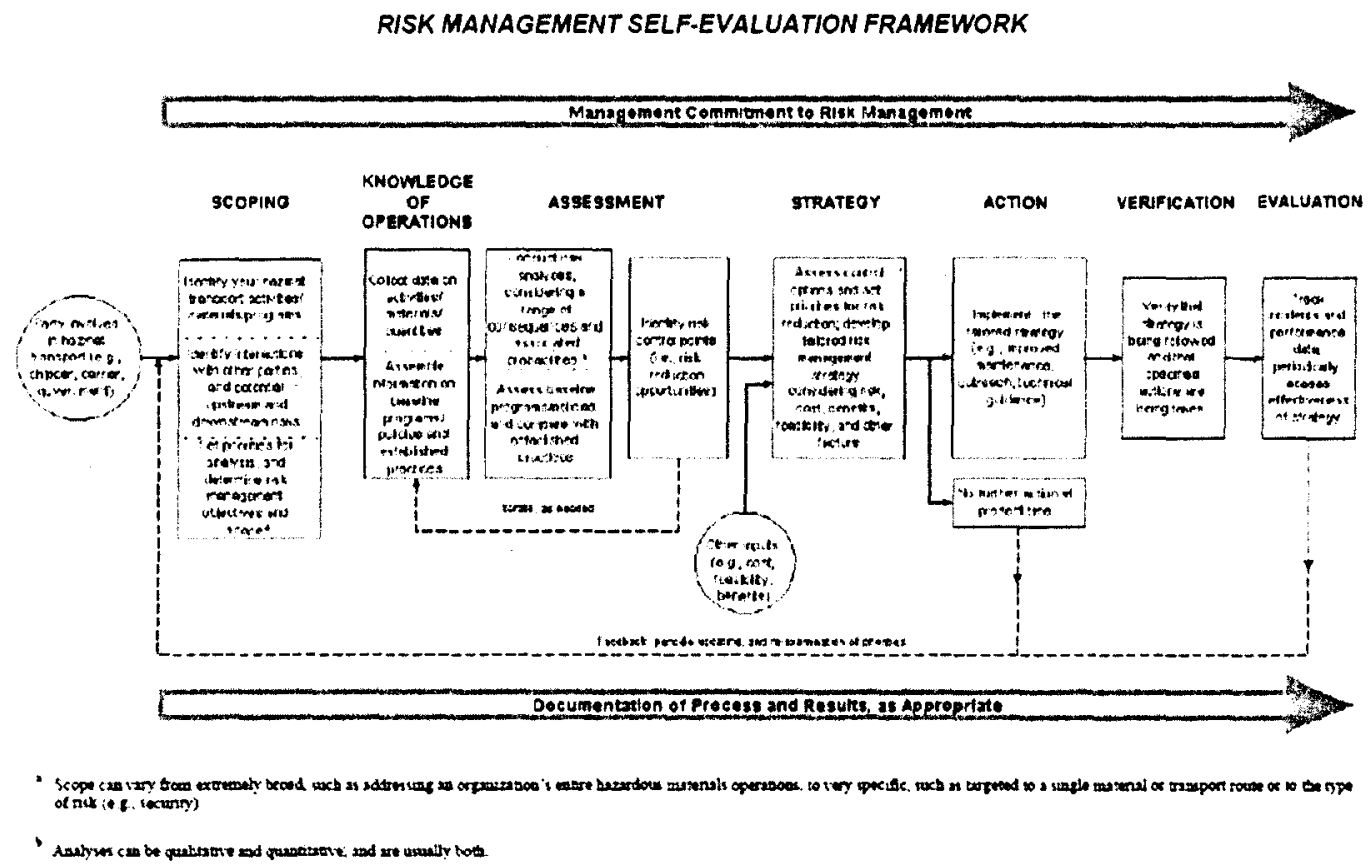

Figure 1 The Diagram for RMSEF

(source: Transportation Security Administration 2002: enhancing security of hazardous materials shipment against acts of terrorism or sabotage using RSPA's, Risk Management Self-Evaluation Frame work Jan. 2002, Web, Page 3.)

In addition to efficient management, technology is also an important tool to help enforce the safe and secured shipment of HazMat.

\subsection{MITIGATING RISK THROUGH TECHNOLOGY}

Research by FMCSA (FMCSA, 2004) indicates that technological measures on the security of HazMat transportation are as important as their management counterpart. Although the detailed information on the technology products, their manufacturers and specific models was not reported in FMCSA (2004), twelve types of technologies were discussed rather extensively. It is also worth mentioning that as of the publication of the study, the government has not provided conditions or subsidies for buying, setting up or 
making use of the technologies. Some HazMat carriers decided to invest on these technologies for the safety and security of their shipments. Below we discuss five technologies that either have been widely adopted or offers great premise for large adoption in the near future by the HazMat shipping industry, or the shipping industry in general.

\section{a. Wireless Satellite and Terrestrial Communications Systems}

The wireless satellite technology uses a satellite-based global positioning system (GPS) to obtain the position of the hauling vehicle based on the easting and northing values. On the other hand, the terrestrial communication system is a land-based technology that permits two-way communications. In the latter system, requests from the dispatcher are generated as many times as wanted, and a reply message from the satellite that shows the position of the truck is transmitted to the dispatcher's computer. Both systems can generate upon request by dispatcher the position of vehicles while en-route.

\section{b. Digital Phone without GPS}

In this technology, the dispatcher and driver communicate using a unique cellular wireless telephone handsets operated by Binary Runtime Environment for Wireless (BREW) technology. Status messaging is used by the driver in responding to integrated work orders transmitted by the dispatcher. Details of an assignment are transmitted if the driver accepts the assignment. The driver uses one of five Marcos transmits progress after the assignment. These Marcos are: accept/reject assignment, arrived, started, stopped, and departed.

This technology is viewed by many trucking companies as a viable approach to 
monitoring the shipment of HazMat. However, there are several concerns regarding its large deployment in the near future. First, the network on the cellular was poor after the truck left the major roadways. Second, proficient use of the system requires intensive training for drivers, and this may not be feasible for small to medium size companies. Third, the messaging requires active and prompt responses between the dispatcher and driver. Making such a commitment can be difficult for either party.

\section{c. Panic Buttons}

This technology is used in conjunction with satellite or terrestrial communication system. When emergency occurs, this technology allows the driver to send a panic message to central dispatcher. Furthermore, the driver can use two methods to disable the vehicle: one is done using a panic button system mounted inside the vehicle; the other is done using a cordless remote panic button carried by the driver. In the remote control case, the roaming distance is about 250 feet.

The panic button system is arguably the most accepted technology in the shipping industry for security control. This is because the system can provide accurate time and location of the incident with effective notification tools. Currently, defense and munitions haulers are required to use this system already. Nevertheless, some fear unintentional tapering of the panic button may raise false alarm. Future improvement in the design of these key fobs is necessary.

\section{d. Global Login}

Global login requires the driver to enter a user ID and password to start the engine of thetruck. This technology is enabled by the on-board software. The user ID and password 
are confirmed within the truck as well as from a remote site with the aid of a wireless communication system. Once the information is confirmed, the driver can drive the truck. If, however, the information is denied, a notice is sent to the dispatcher to take proper actions. The dispatcher can decide to remotely disable the truck or any other better option.

The Global login technology has performed well in the test, and it does not interfere with operations. On average, $\log$ in takes approximately 33 seconds. The major disadvantage of this system is the burden for drivers who make multiple stops to login all the time, and the possibility of the driver forgetting his user ID and/or password can be disruptive These two concerns are addressed by biometric login systems.

\section{e. Biometric Global Login}

The biometric global login system is an on-board central processing unit operated by proprietary firmware. In this technology, instead of the login name and password needed by the global login system, a smart card and fingerprint is required to operate the truck. A link from the system to the dispatcher is not required.

The biometric login concept is appealing to many. Unfortunately, it exhibited several drawbacks upon actual testing. First, the system requires a specific range of temperature for finger to be read. Second, the driver cannot login in if his/her smart card is missing. Third, the dispatchers could not monitor the trucks once it is started.

In summary, public safety and security concerns are inherited from transporting hazardous materials. Thus, mitigating risks associated with HazMat transportation has received growing attention from DOT and TSA, especially after the 911 attack in the 
U.S. This survey-based empirical study aims to gain knowledge on the commodity flows of HazMat in the U.S., and to evaluate the current state of risk reduction efforts both through management and technology in the HazMat shipping industry, and finally to compare the effectiveness of existing and/or potential risk reduction measures. Ultimately, we make recommendations to authorities such as TSA and FMCSA on strengthening the security programs in HazMat transportation, as well as to HazMat carriers on selecting effective means to reduce safety and security risks.

The remaining of the report is organized as follows. Chapter 3 discusses the methodology we use to design the questionnaire. Chapter 4 describes the method of collecting data from transportation authorities as well as shippers. Chapter 5 analyzes the results from the survey, and finally Chapter 6 offers conclusions and recommendations. 


\section{CHAPTER 3 METHODOLOGY}

The objective of our research is to understand the risk involved with HazMat shipment and the mitigation strategy/tools used in an effort to lessen the impact that disasters might have on people, property and environment through actions taken before a disaster strikes. To meet these objectives, we created a survey to the stakeholders (carrier and Manufacturer) to understand the state of the industry. This chapter describes the design and methodology of the survey.

\subsection{RISK EXPOSURE DIAGRAM IN HAZMAT TRANSPORTATION}

A hazardous material risk exposure diagram was first developed as shown in Figure 2. The main purpose of developing this footprint of risks is to help create an effective and comprehensive questionnaire that considers each stage of the transportation process. In particular, there are three stages in the diagram: departure, En-Route and arrival. We then identify possible risks at each stage. First, in the departure stage, major risks include poor hiring, sabotage, non-compliance with standard procedures, etc. Second, the EnRoute or In-Transit stage is exposed to most and greatest risks. The source of risks in this stage includes exhausted driver, hijacking, drug abuse, accidents, among others. Without a doubt, this stage deserves dynamic and constant monitoring in an effort to reducing risks. Third, the arrival stage involves a risk of wrong delivery when the wrong recipient does not follow standard handling of the HazMat. 
Once risks are identified for each stage, we develop associated strategies to mitigate these risks. In the departure stage, these strategies are more of management tactics such as background checks for new hiring, security training programs, and safety drills. In the transit (En-Route) stage, the strategies are a mixture of technological and management measures, with the focus on constant monitoring of the shipment. These strategies range from alternative route planning, to communication systems with new technologies, to scheduled rest stops, etc. Finally, in the arrival stage, we suggest to follow proper handoff and communication procedures for HazMat delivery.

Based on these identified risks and risk mitigation strategies we develop a questionnaire, which we shall discuss below.

\subsection{SURVEY DESIGN}

The objective of the survey is to gather information to help understand what risks carriers and/or manufacturers consider before transporting a hazardous material. The survey questions were categorized into three different sections: The first section focused on the company's profile, the purpose was to capture information such as:

1. Company name

2. Company size

3. Company location

4. Organization Description (carrier or Manufacture or Both)

5. Logistics Operations 


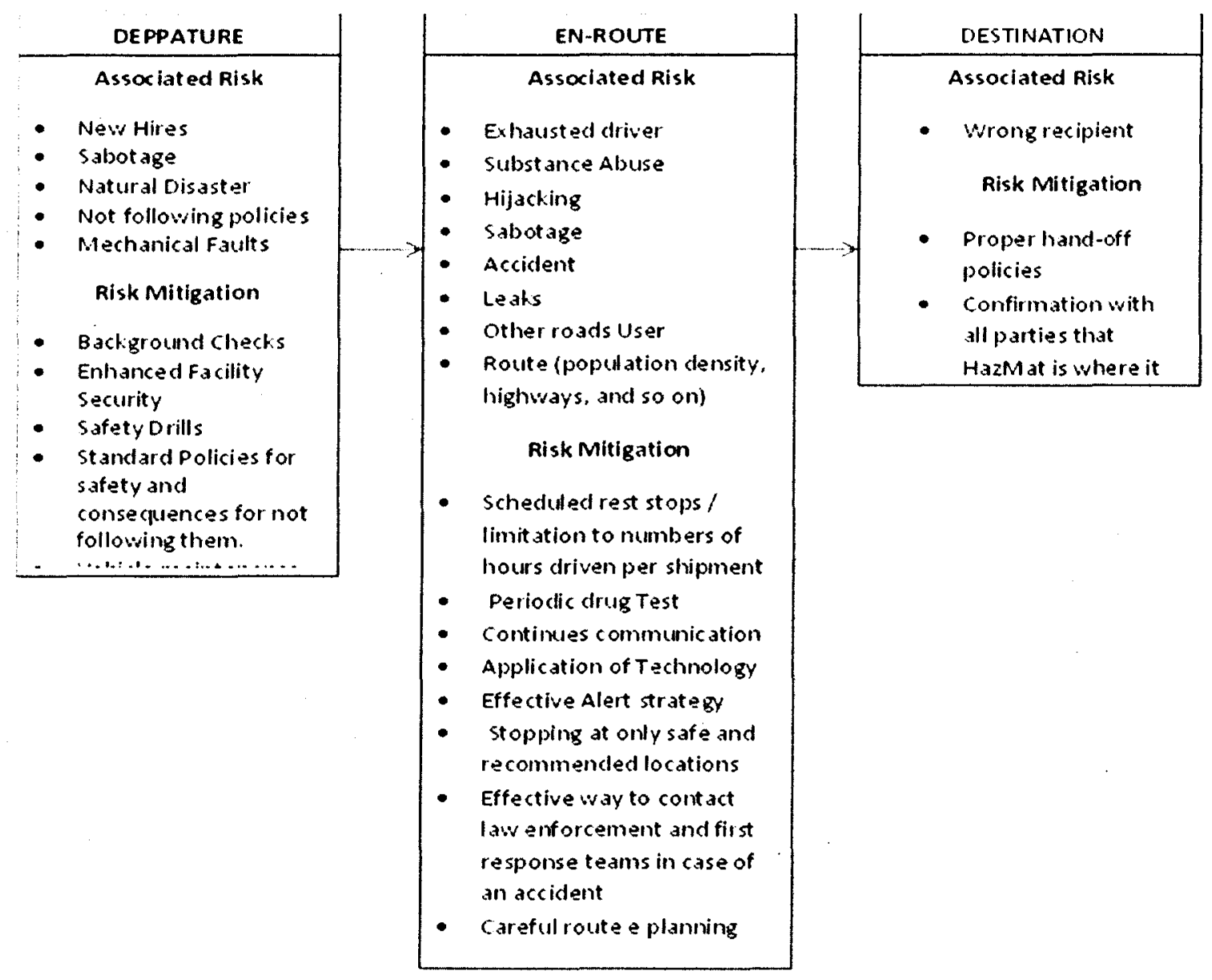

Figure 2 Risk Exposure Diagram

In particular, questions 1,2 and 3 required text responses, while the other questions had options to pick from. The question above will be used as a good comparable measure for comparing size and risk management strategy. The assumption is that larger companies will transport more types of commodities at longer distances. Also the larger companies will have the financial capabilities of using more state-of-art technology for protecting the commodity en-route.

The second section of the survey was designed to give more insight to commodity flow, being that hazardous material transporters move a wide variety of HazMat commodities. The following questions below were asked in the section: 
6. Transportation Mode

7. HAZMAT classification

8. Total Number of outbound shipments per year

9. Top 3 HAZMAT you transport

10. List the three most frequent destination by State

11. Average weight in pounds (lb.) per shipment

12. Average mileage per shipment

13. Number of Vehicle

The purpose of this survey section was to identify what different modes of transportation a hazardous material could go through before getting to its final destination. Also, the section will be used to distinguish what category the hazardous material will be classified under and the average weight and distance of transport for each shipment. Question 13 should have a very close correlation with the size of the company. So for small companies, the number of vehicle managed at a given time should be small and vice versa.

The third section of this survey deals with the risk mitigation tools that the participant uses to make sure that their commodities are in safe hands and secured when en-route. The questions in this section are designed to cover most aspect of risk management for HazMat. The questions focused on issues related to employee's characteristics, safety and security awareness training, risk associated with HazMat, technology, preparedness level and future possible improvement for a HazMat to be more manageable. Below shows how the questions are asked in segments. 


\section{4-15. Background checks}

\section{6-19. Associated risks and their ranking}

20-26. Current precautionary measures and techniques, and their ranking

27-29. Future risk mitigation plans

Particularly, questions 14 and 15 deal with background checks conducted for new hires, while question 16 was to see if they had safety and security awareness programs for employees, and questions 17 through 19 asked participants to indicate what they think are the associated risks with HazMat shipment, what measures they took to secure their shipment and also what technology they currently used to reduce this vulnerability, respectively. The subsequent questions addressed the preparedness level of the carrier's individual firm as well as the entire transportation industry. Then, questions 27 through 29 asked if the economy had affected their commitment to safety and if they planned on strengthening security through awareness. Finally, question 30 asked participants to openly comment on how to improve security in the motor transportation sector. Participants were also given the opportunity to suggest ideas and elaborate more on their suggested measures. 


\section{CHAPTER 4 DATA COLLECTION}

The respondent of this survey were carriers and manufacturers who deal with HazMat first hand, because we believe they have the best knowledge daily activities devoted to safety and security of HazMat shipment. There was no restriction on size or location of the participant and that was because we wanted to be able to compare result. This will enable us to see how size or location of the participant relates to their risk mitigation capabilities. All responses were voluntarily obtained and a total of 30 usable surveys were received from participants.

Respondents were initially identified from an online database www.tanktransport.com. This is a website where carriers advertise their services and it was last updated last in 2011. This online database has a directory that allows for viewers to filter carriers based on their home states and the materials they transport. Because not every carrier in this database hauls HazMat, we filtered out carriers that fit the targeted hazardous materials based on TSA classification introduced in Chapter 2. The database also provides us with contacts, addresses and phone numbers of selected carriers.

Initial phone calls were made to possible participant to establish a contact person and see if they were interested in participating. Respondent were given three different options on how to complete the survey, depending on which was more suitable to them. Surveys were distributed using an online survey company called SURVS. Of the 30 responses, 
only 4 had information that was usable from the online survey. A total of 15 responses were attained by mail and the remaining 19 by phone.

Besides manufacturers and carriers, transportation officials/agencies are also important stakeholders in HazMat transportation, because they are the ones who oversee the shipping industries and design the related policies. Therefore, we designed a separate survey for government agencies. Since, these government agencies enact the policies and enforce the regulation, we hoped to get their view of how both public safety and security risks associated with HazMat should be mitigated. Department of transportation is an ideal agency and we identified contacts or addresses from the DOT websites at the state level. All 50 states' DOT were sent hard copies of the survey. Only 5 surveys were returned by states' DOT. Due to the low response rate, we did not include the data in our final analysis. 


\section{CHAPTER 5 SURVEY RESULT AND DATA ANALYSIS}

The survey data were inputted into an EXCEL spreadsheet to summarize the data and obtain the results. Using EXCEL as a centralized location for all survey responses collected over the phone, internet and hard copy, we were able to identify on duplicate response.

\subsection{COMPANY INFORMATION}

Thirty companies participated in this survey, of which 3 responses were collected from the internet, 12 responses were collected by phone calls, and the rest 15 responses were collected via mail. 28 of these companies claimed themselves to be carriers and the other 2 were manufacturers. These participants are located in 19 different states, and their size varies from 8 employees to 16,500 employees. In this report, we divide these participants into three groups: Group One- small companies with 1 - 100 employees; Group Twomedium size companies with 101 - 1000 employees; and finally large companies with more than 1000 employees. Some of the following results related to risk management were analyzed based on company size.

Tables 1 through 3 show the distribution of the respondents according to their size and their geographical location. A total of 13 companies are small businesses making it the highest group of all respondents, followed by the medium size companies with a total of 10 , and then by the large business with a total of 7 . 
The geographical distribution of respondents was mostly random across the U.S but some states had more responses than others. There were 4 responses from Arkansas and 3 from Kentucky, Nebraska, and Alabama respectively. Also, 2 responses from South Carolina and every other state had 1 response each.

Table 1 Small Business

\begin{tabular}{|c|l|l|}
\hline \multicolumn{3}{|c|}{ SMALL BUSINESS } \\
\hline Number of employees & Company Location & $\begin{array}{l}\text { Carrier or } \\
\text { Manufacturer }\end{array}$ \\
\hline 100 & Tracy, CA & Carrier \\
\hline 20 & South Plainfield, NJ & Carrier \\
\hline 55 & Houston, TX & Carrier \\
\hline 20 & KC,MO & Carrier \\
\hline 14 & Jeffersonville, VT & Manufacturer \\
\hline 100 & Selma, NC & Carrier \\
\hline 19 & Charleston, SC & Carrier \\
\hline 40 & South Carolina & Carrier \\
\hline 8 & Kansas City & Manufacturer \\
\hline 50 & N. Augusta, SC & Carrier \\
\hline 100 & Dolomite, AL & Carrier \\
\hline 30 & Kansas City, KS & Carrier \\
\hline $60+$ & Aurora, NC & Carrier \\
\hline
\end{tabular}

Table 2 Medium Business

\begin{tabular}{|c|l|l|}
\hline \multicolumn{3}{|c|}{ MEDIUM BUSINESS } \\
\hline Number of employees & Company Location & $\begin{array}{l}\text { Carrier or } \\
\text { Manufacturer }\end{array}$ \\
\hline 500 & Hartsfield, Alabama & Carrier \\
\hline 350 & Pittsburg, PA & Carrier \\
\hline 200 & Wooster, OH & Carrier \\
\hline 300 & Louisville, KY & Carrier \\
\hline $600+$ & North Little Rock, AR & Carrier \\
\hline 300 & Omaha, Ne & Carrier \\
\hline 600 & Oak, IL & Carrier \\
\hline 300 & Jackson, MS & Carrier \\
\hline 138 & Fairbanks, AK & Carrier \\
\hline 300 & Louisville, KY & Carrier \\
\hline
\end{tabular}


Table 3 Large Business

\begin{tabular}{|c|l|l|}
\hline \multicolumn{3}{|c|}{ LARGE BUSINESS } \\
\hline Number of employees & Company Location & $\begin{array}{l}\text { Carrier or } \\
\text { Manufacturer }\end{array}$ \\
\hline 4000 & Indianapolis, IN & Carrier \\
\hline 1000 & Troy, AL & Carrier \\
\hline 1500 & Murray, KY & Carrier \\
\hline 6100 & Lincoln, NE & Carrier \\
\hline 1100 & Omaha, NE & Carrier \\
\hline 16500 & Lovell, AR & Carrier \\
\hline 2000 & Albany, NY & Carrier \\
\hline
\end{tabular}

\subsection{COMMODITY FLOW}

Among 30 replies, 77 percent use highway mode, 13 percent use inter-mode of highway and railway, 6 percent use inter-mode of highway and waterway and finally 3 percent use highway, railway and waterways for the shipment of their hazardous material.

HazMat characteristics are plotted in Figure. 3. Eighty percent of respondents report that they transport corrosive materials. This is not surprising because corrosive materials which are acids or alkalis such as sulfuric acid, hydrochloric acids and sodium hydroxide are heavily used commodities in several industrial applications. According to the survey results, flammable liquid (e.g., gasoline) is the second commodity that most carriers transport ( $74 \%$ of the participants). This is due to the high demand of the auto gasoline all over the country. These two categories are followed by flammable solid (58\%), oxidizer $(48 \%)$, gases $(42 \%)$, toxic $(35 \%)$, explosives $(6.5 \%)$, and radioactive materials $(3.2 \%)$. 


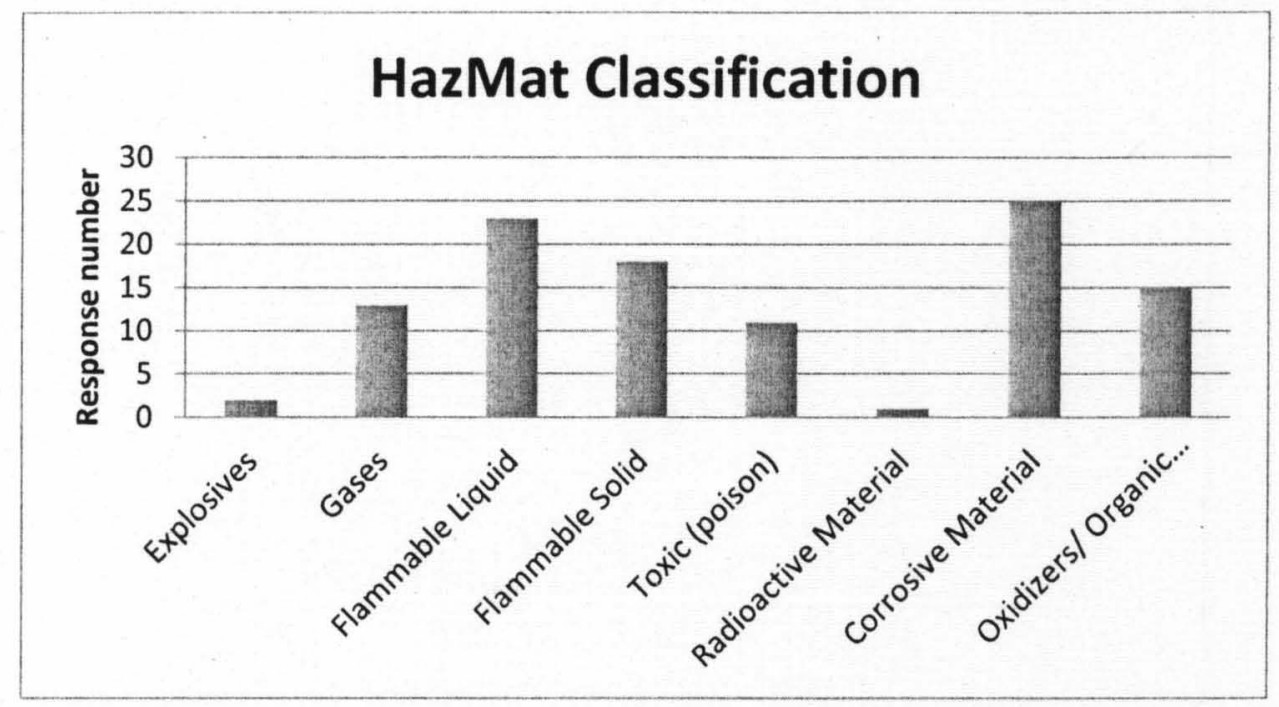

Figure 3: HAZMAT Characteristics

The survey results also show that about sixty-six percent of respondents have shipments that are over 20,000 pounds per shipment. There is a similar pattern for less than 5,000 pounds per shipment and between $5,000-10,000$ pounds per shipment with an average of fifteen percent.

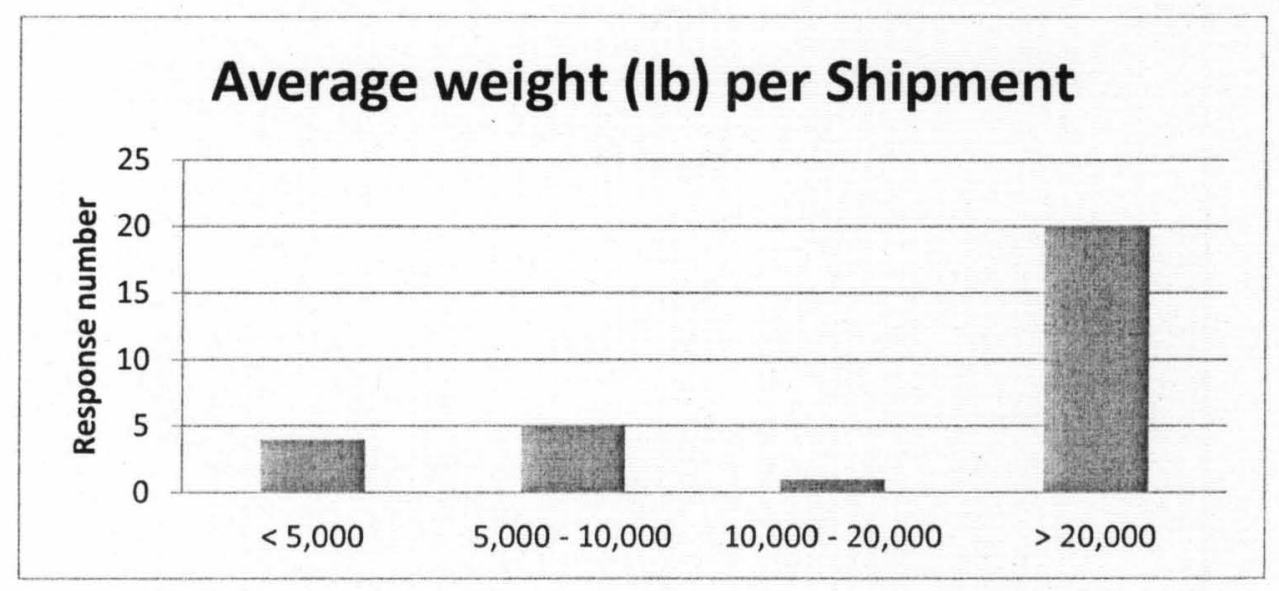

Figure 4: Average Wt. (lbs.)/shipment

The majority of respondents (57 percent) indicated that their drivers drive between 500 miles and 1000 miles per shipment. This is followed by those who drive less than 500 
miles per shipment (20 percent). With an average of a little over 11 percent, these drivers' average mileage per shipment was between 1000-2000 miles/shipment and 64 percent of the shippers deliver greater than 2000 mile/shipment. The detailed survey results further showed that neither the shipping tonnage nor the shipping mileage is related to company size or HazMat characteristics. However, those shippers who ship low volume $(<1000$ tons/shipment) normally deliver that HazMat to a closer area $(<500$ miles/shipment)

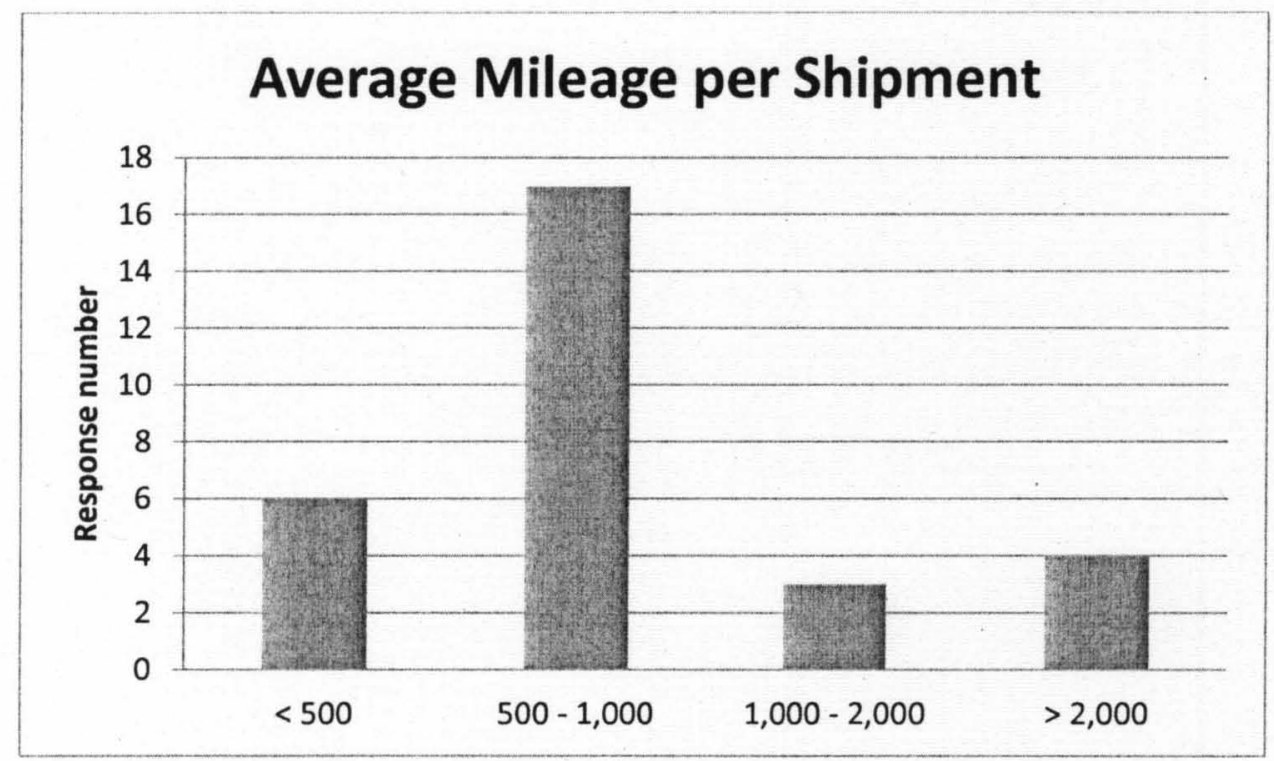

Figure 5 Average Mileages/ Shipment

\subsection{RISK MITIGATION}

This part of the survey aims to find out the current awareness, preparedness and potential actions of risk mitigation of HazMat highway shipments. The survey questionnaire was designed with groups of questions targeting background checks and route protections to find out the awareness of risk mitigation. This is followed by a group of questions on 
technologies that are currently used by shippers and carriers. Finally, the participants were asked question related to future investment and suggestions on risk mitigation. The results to these questions are discussed as follows.

The survey found that regardless of company size, all of the participants do background check upon hiring. Among the four different backgrounds check programs given in the questionnaire for the respondents to select that they felt would most help hire the right person for the job, the most popular choice was looking into their criminal past with 90 percent of respondent choosing this program. This was followed closely. by 'social security verification' and 'immigration status verification' chosen by nearly 87 and 80 percent respectively. 50 percent of the shippers looked into potential hires 'motor vehicle history.' Among the 30 participants, 7 did additional background checks including employment history check and drug check (Figure 6)

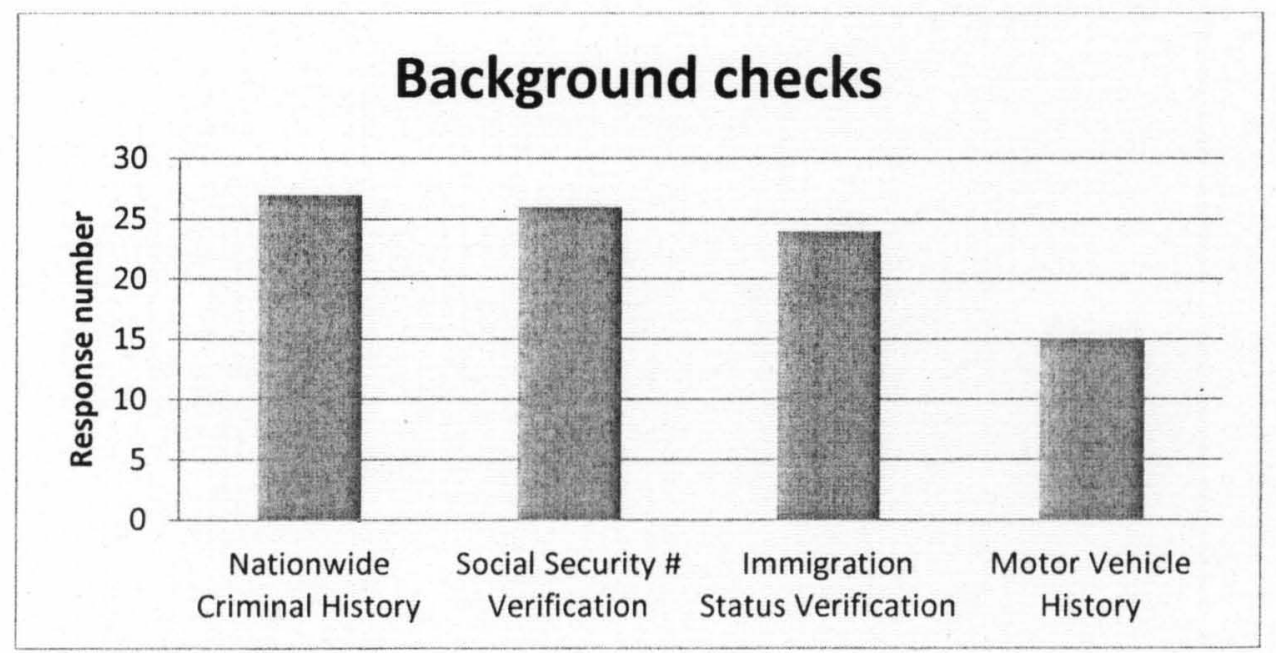

Figure 6: Hiring: Background Checks Required 
Following the background check, the participants were asked questions regarding security/risk awareness. All of the participants provided their employees with security awareness training.

To find out the shipment associated risks, the shippers were asked to choose from a list related to highway risks (Figure 7). The majority of respondents (94 percent) indicated 'accidents' as the number one risk associated with shipment of HazMat on U.S highways. Both 'vehicle malfunction' and 'other road user' have a response of 35 percent making them the second highest risk associated with HazMat shipment, while the least popular was 'sabotage' with only 13 percent choosing this associated risk. Among those (8 companies) who chose leaks as an associated risk, most of them are small companies with less than 50 employees. This could be related to the affordability of those companies to regularly check-up and maintain their transport vehicles.

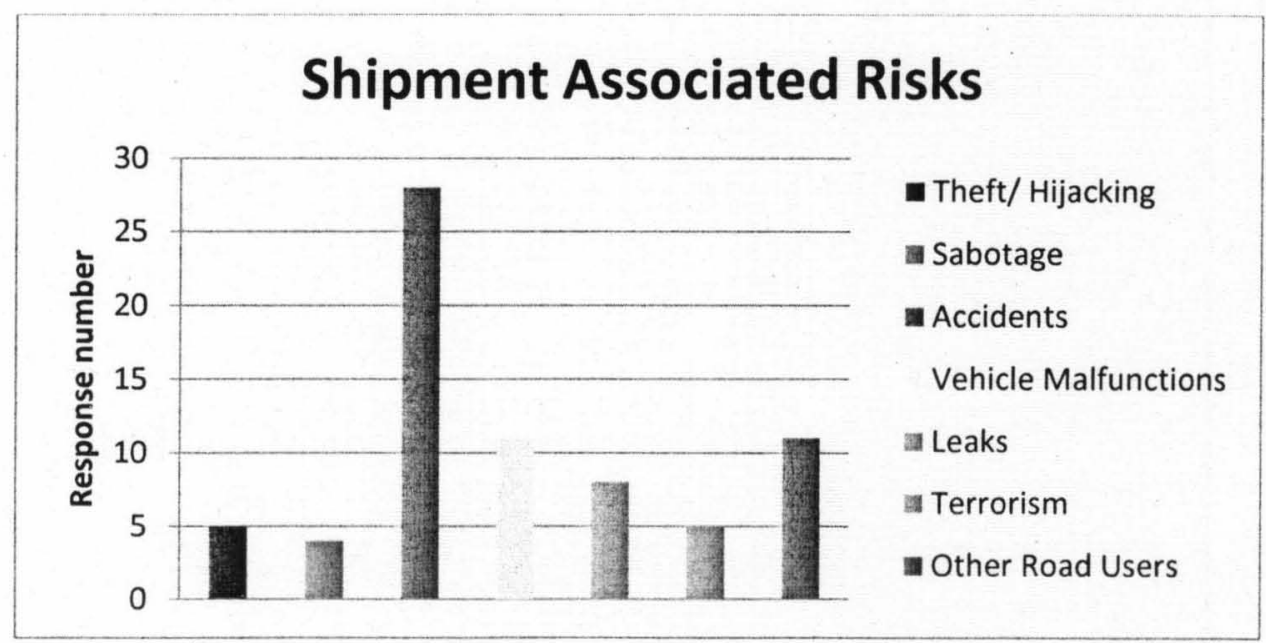

Figure 7: Shipment Associated Risks

To further find out risk awareness and preparedness of HazMat shippers, the participants were asked which of the precautionary measures they currently exploit in protecting their 
supply chains (Figure 8). At 83 percent 'Standard security inspection policy and procedures' was considered to be the most helpful tool used as a precautionary measure for a safer and secured shipment. This was followed closely by 'careful route planning' with 80 percent choosing this approach. However, to further follow up the "routing" question, only $47 \%$ of the companies said they planned secondary routing for HazMat shipment, while $10 \%$ of them indicate whether or not secondary route is planned depends on the shipping mileage (with "yes" for $<100$ miles). $77 \%$ of the companies indicated that they had standard reporting policies and procedures. About half of the participants replied that they follow TSA recommendations, have standard alert protocols, and require continuous communications among all parties. 25 percent of respondent agrees to use two drivers to ship HazMat commodities help for safer shipment. Although most of these companies are medium or large companies with more than 500 employees, it should also be noted that more than half of the big companies that participated this survey indicated that they do not use two drivers as a risk precautionary measure. This is probably due to the affordability of hiring. The survey results also found that 'Armed Escort' was proven to be unnecessary with 0 percent response. 


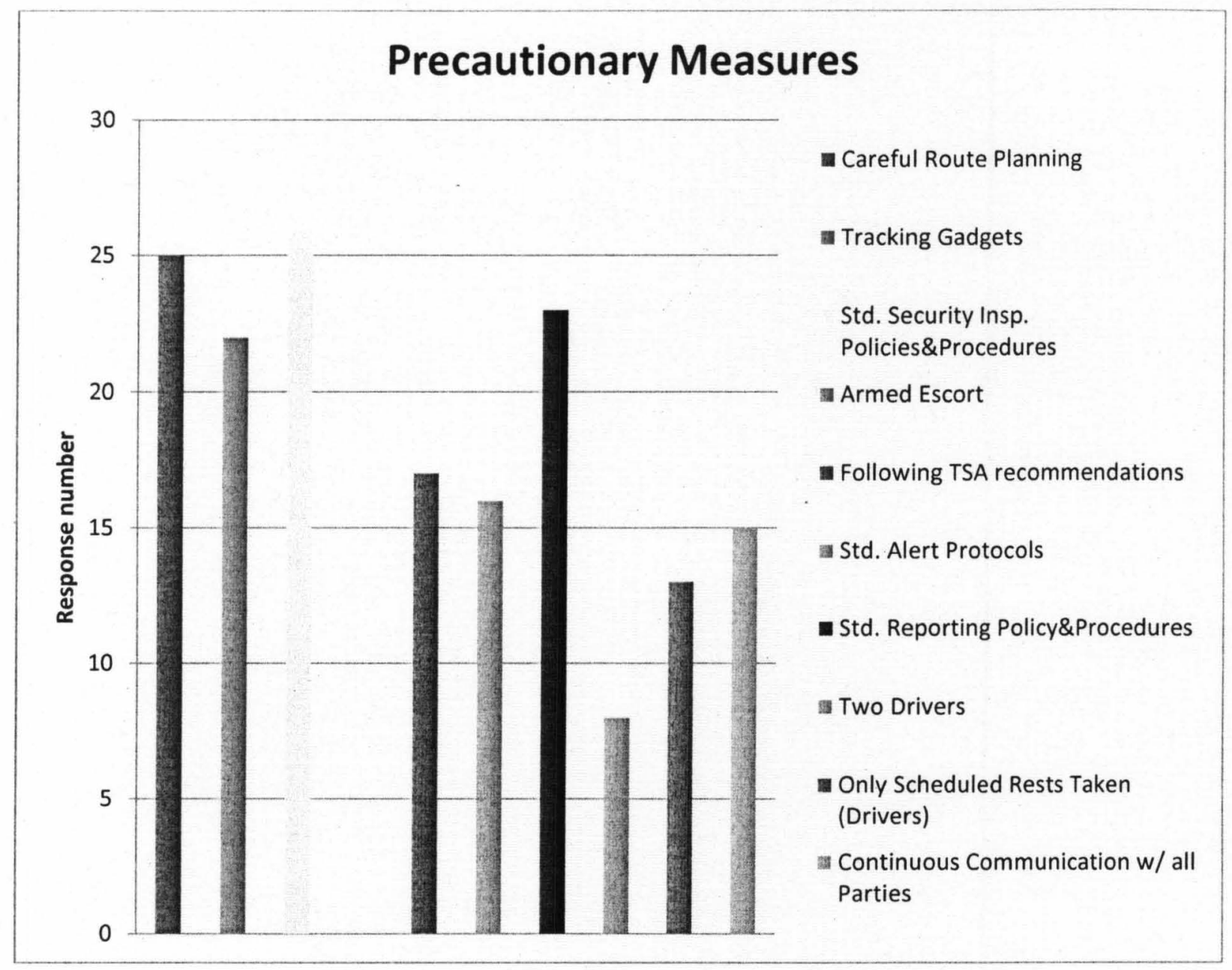

Figure 8: Precautionary Measures

The participants were also asked for their opinions to rank the most important precautionary measure. Among the replies that are collected, 9 companies indicated that following TSA policies was the most important measure, 9 companies thought tracking/GPS was the most important, 6 put routing carefully as their top one measure, and there are 4 companies ranked communication as their No. 1 precautionary measure. 


\section{Most Effective Precautionary Measures}

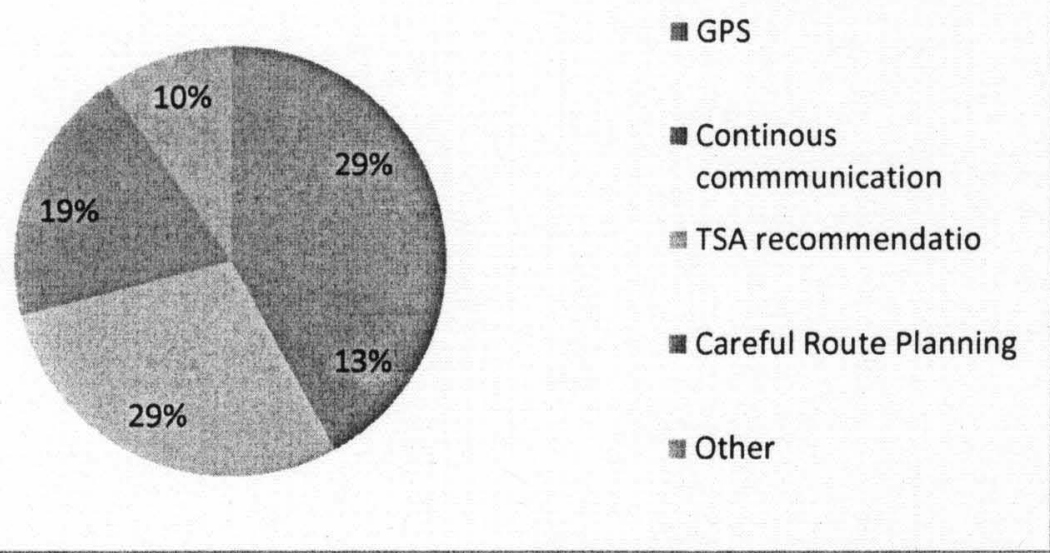

Figure 9: No. 1 Precautionary Measure

In order to find out the usage of the precautionary technologies that are currently available on the market, participants were given options covering most affordable technologies such as cell phone and pagers to quite expensive technologies such as RFID. Respondents chose 'satellite tracking (GPS) and 'cell phone or pager' as the technology devices they currently use with a response of 80 percent and 74 percent, respectively. This result is regardless of company size, HazMat characteristics, shipping tonnage and mileage. This makes sense because these two technologies are the most affordable and accessible compared to the other proposed technology. Following these two devices is 'in-vehicle mounted computers' with 52 percent utilization. From Figure 10, it can also be noticed that remote vehicle disabling, RFID, barcodes, and electronic cargo seal are the four least favorable technologies. Those three companies who indicated that they are using RFID for example are either small companies or mid-size companies. This 
indicates that the applying of precautionary technologies only depends on company's policy.

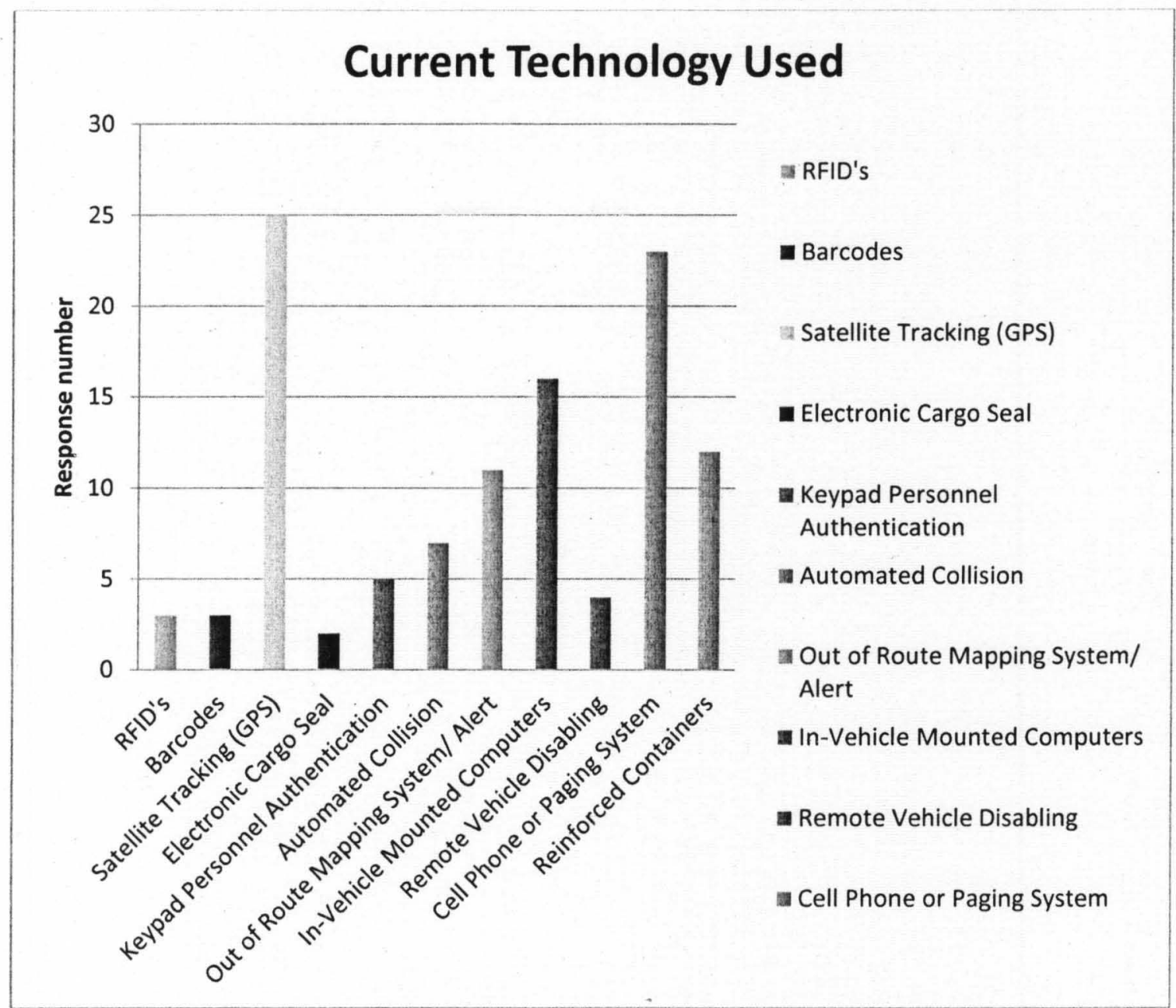

Figure 10: Current Technologies Used

Similar to the precautionary measures, the participants were also asked to rank their top one important precautionary technology. Among the collected results, 16 companies indicated that GPS was the most important technology and another 9 companies ranked cell phone/pager as the most important technology. This result corresponds to the high 
usage of these two technologies ( $80 \%$ and $74 \%$, respectively) among the users. This is probably due to the effectiveness and popularity of these two technologies.

\section{Most Effective Technology}

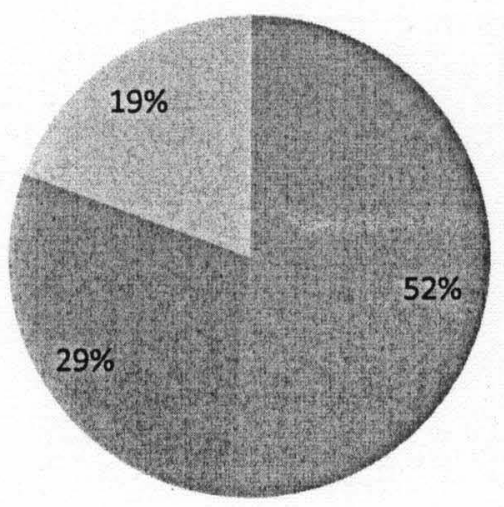

GPS

출 Cell Phone

Other

Figure 11: Most effective Technology

To find out the awareness and preparedness of HazMat highway risk mitigation, the participants were asked to rate their preparedness in the case of any safety or security event on a "one" (least prepared) to "five" (best prepared) scale with "three" indicating "average." The results are summarized in Figure 12. About 94 percent of respondents rated their preparedness above average (higher than 3 ). This shows that there is a clear appreciation for safety amongst stakeholders. Of those, 29 percent gave their company a rating of 'five' and 45 percent a rating of 'four', making it the highest rating. About 6.5 percent gave a rating of 'two' making the lowest rating assigned by respondents. 


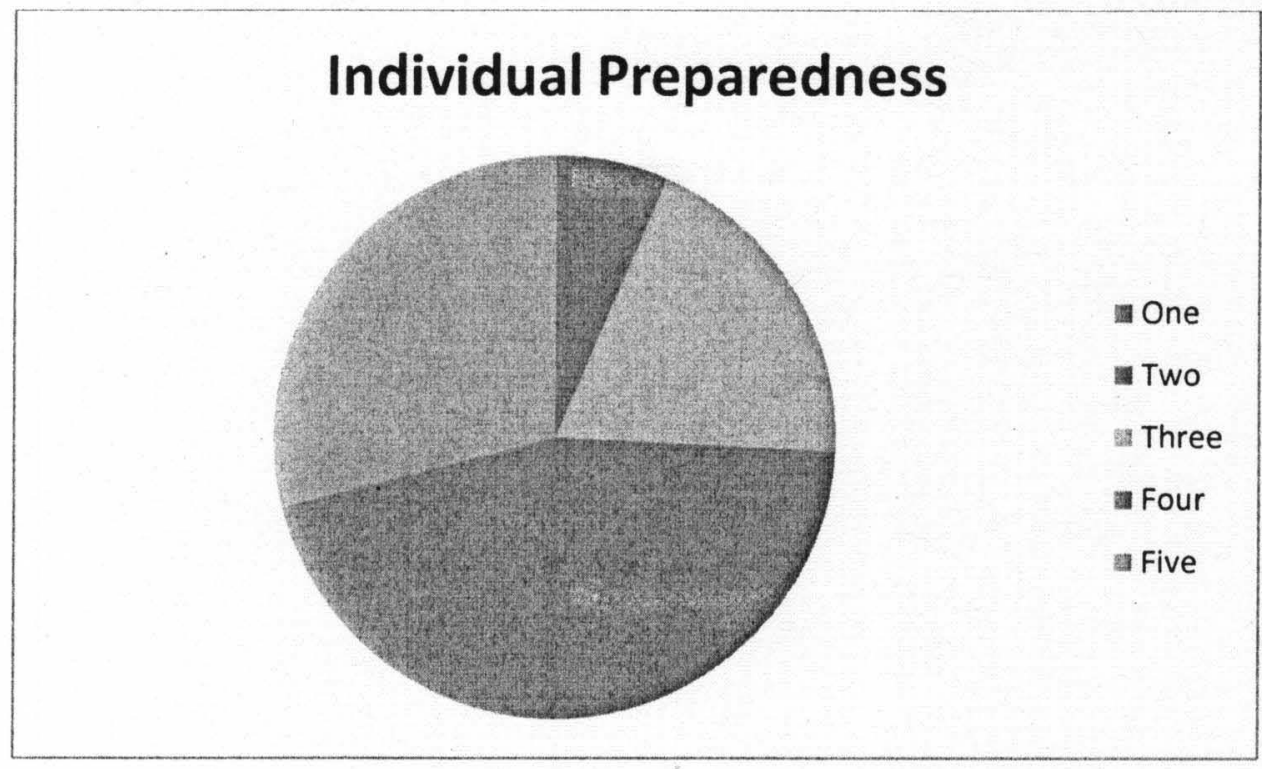

Figure 12: Individual Preparedness

Similarly, respondent were asked to rate the entire industries preparedness in respect to safety or/and security issues (Figure 13). 'Two' and 'Three' both had a rating of 29 percent response for industry preparedness. This contradict the previous question where more than half gave themselves a rating of 'four' or higher, whereas, more than half gave the industry preparedness a rating of 'three' or lower. 


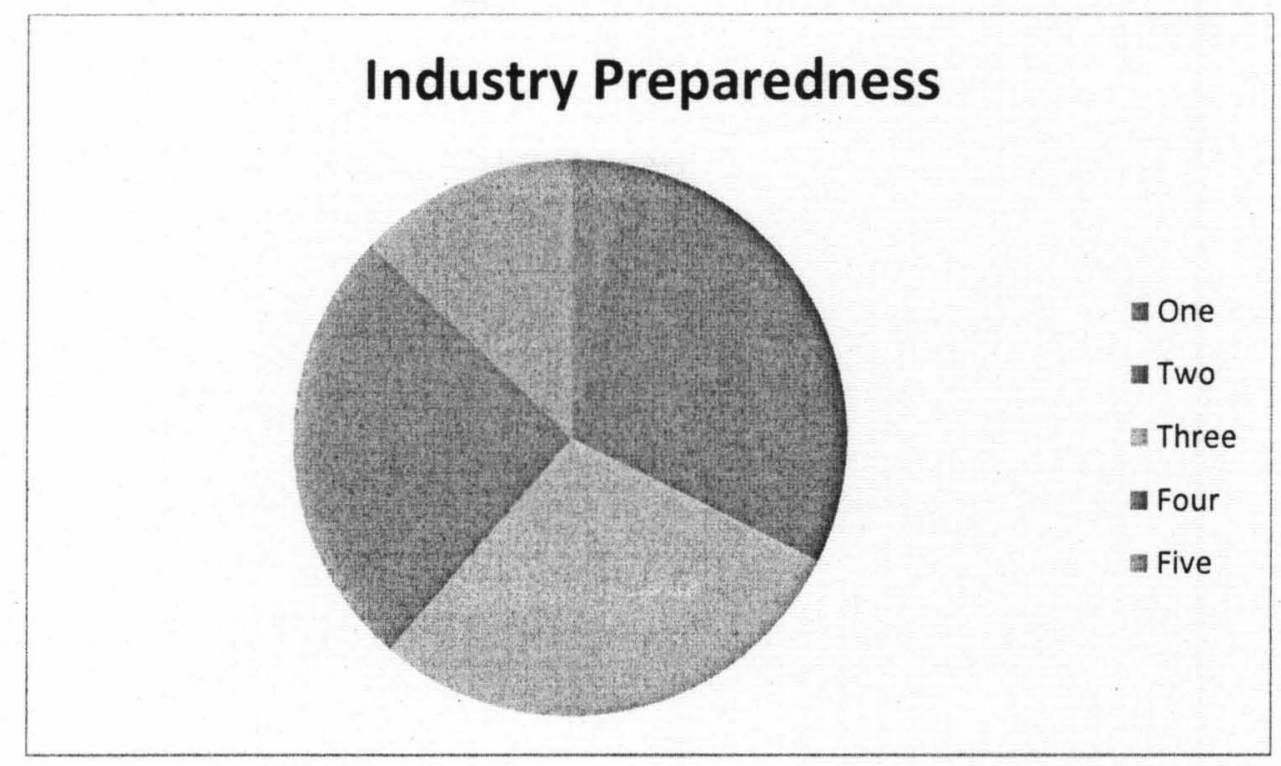

Figure 13: Industry preparedness

To find out industrial investment regarding risk mitigations, the respondents were asked whether they had suffered significant financial cuts on their security programs due to the current economic downturn, none of them indicated that they had any financial cut. On the other hand, $53 \%$ of the respondents with a mixture of different company sizes replied that they would strengthen their security measures. To follow up this question, the participants were further asked how they would suggest strengthening risk mitigation of HazMat highway shipment (Figure 12). Safer and secured parking at official truck stops topped the list with 74 percent respondents citing this issue as the best way to improve safety. Educating other road users (70 percent), more staff training (55 percent) and improvement to facility security (58 percent) were also considered important issues in safety. This is consistent with the finding that $94 \%$ respondents chose "accident" as the No. 1 risk associated with transporting HazMat on highways. Training was also deemed significant with nearly two-thirds of respondents citing this as paramount in improving 
safety. Stricter controls on illegal immigrant, improvement to vehicle security systems and strict enforcement of TSA regulation were all considered somewhat important; they all had a 45 percent quote each.

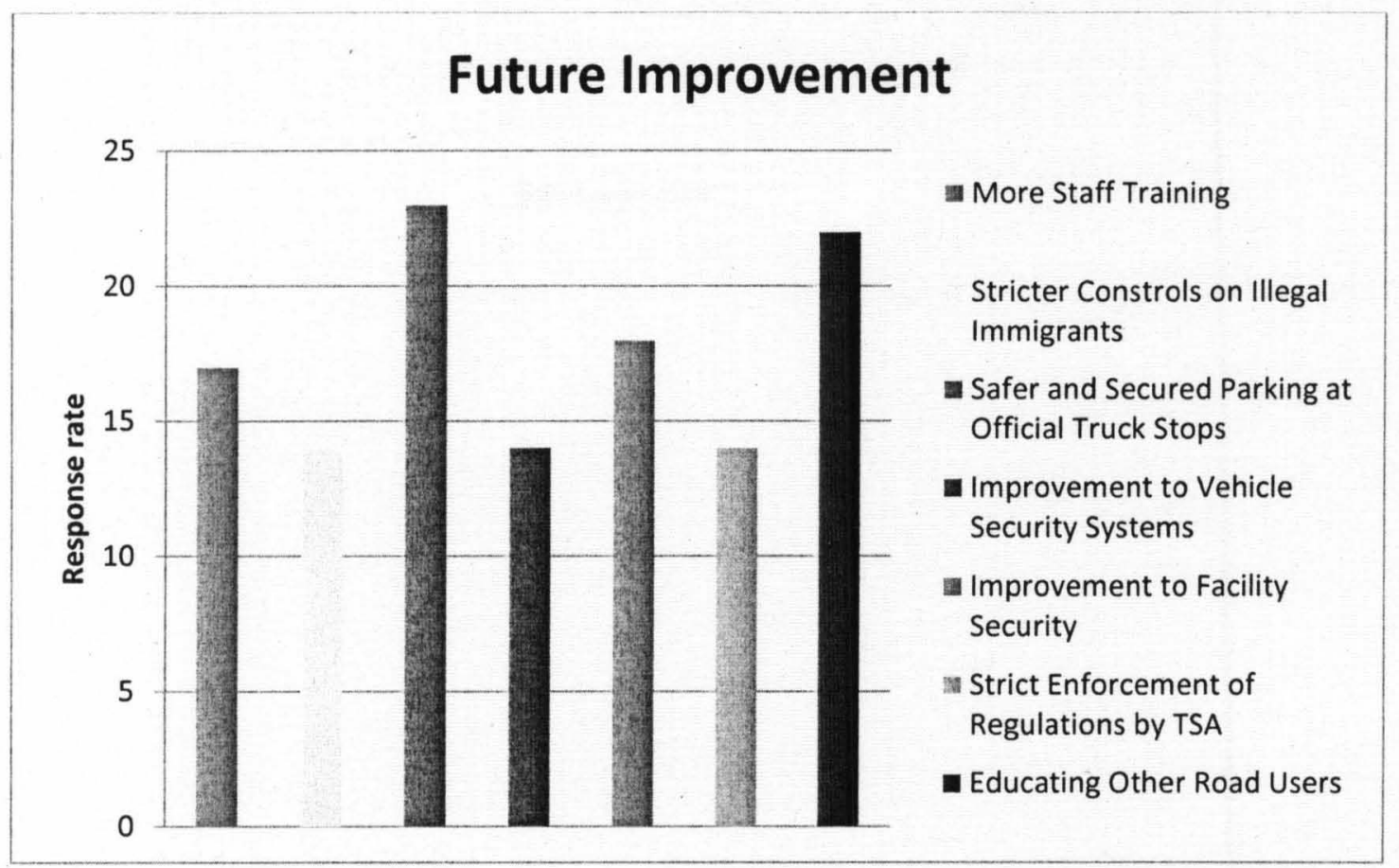

Figure 14: Future Improvement 


\section{CHAPTER 6: CONCLUSIONS AND RECOMMENDATION}

The transportation of HazMat on our highways is envisioned to continuously grow in the near future, thus more attention is needed on the safety and security in transporting these commodities. As mentioned previously, the number of accidents per year on U.S. highways has continued to increase, and their impact on HazMat transportation and thus on public safety can be rather devastating. The safety awareness programs and security risk management tools that all stakeholders (carriers, transportation agencies, drivers, etc.) actively employ can help prevent destructive events. This study designed two questionnaires (one for HazMat carriers, one for transportation agencies) to survey the commodity flow on HazMat, the risks associated with highway transportation of HazMat, and the measures to mitigate these risks.

Our data analysis yields the following observations. First, roughly $50 \%$ (15 companies of the 30 respondents) of HazMat carriers we contacted are small size businesses with 100 employees or fewer. On the other hand, we found no correlation between company size and the shipping tonnage per shipment or the shipping mileage per shipment, although low shipping volume $(<1000$ pounds/shipment) does correlates positively to shorter shipping distance $(<500$ miles/shipment). Second, the most transported HazMat is corrosive material (about $80 \%$ ) followed by flammable liquid such as gasoline (74\%) and flammable solids (58\%). This may suggest a focus area in developing effective risk mitigation strategies. Third, two human resources related management tools for reducing risks, namely the background checks upon hiring and the security awareness training, are 
adopted by all 30 respondents. It is worth noting that only 7 of the 30 respondents conduct more intense background checks such as periodic drug tests and employment history check. We believe that this is an area of improvement that all HazMat carriers need to consider. Fourth, there is a great consensus (94\%) among all respondents that 'road accident' is the most concerning risk in HazMat shipment. This is followed by 'vehicle malfunction' and 'other road user'. We believe that 'other road users' is just a different perspective to 'road accidents,' which leads to an even higher percentage for 'road accident'. Fifth, addressing the concern on 'road accident', 70\% respondents chose 'Educating other road users' as their suggested future improvement, only second to 'safer and secured parking at official truck stops' by $74 \%$ respondents. Sixth, all respondents use one form or the other to either track the shipment or communicate with drivers. GPS and cell phones top the list of all given technologies. This may be largely due to the affordability of these two technologies. Furthermore, these GPS and cell phones are also the top two "most effective technology" viewed by 30 respondents, despite sophisticated design and appealing features from other proposed technologies. Finally, it is interesting to note that the three companies that have invested in expensive systems such as RFID are either medium or small size companies. This indicates that a company's investment in security programs does not correlate with their size; rather it is determined by their management's commitment to security and public safety.

The above conclusions lead to several recommendations. First, government agencies such as TSA should view small trucking companies as equally important as large companies, especially in HazMat shipping industry. They not only have significant share of shipping volume, but are equally or even more invested in strengthening their security programs. 
Any future pilot studies should eagerly engage these small size carriers. Second, since corrosive material is the most transported HazMat on U.S. highway, developing and reinforcing risk mitigation measures specific to this material is more cost effective than a general treatment. Third, we recommend that all HazMat carriers enforce periodic drug tests to minimize the risks in transit stage. This is a relatively low-cost effort with significant benefit. Fourth, road accident is the top concern expressed by almost all HazMat carriers, thus we recommend a joint effort between HazMat safety and public road safety. Propagandas such as defensive driving for public, safety and security training on highway driving for public may be the initial effort in this endeavor. Finally, future technology development of tracking and communication systems should give primary consideration to affordability instead of sophisticated functions.

Much to our surprise, state transportation agencies did not show much interest in this survey. One of our future researches is to engage them in this study and obtain their perspectives on existing policies on risk mitigation in transporting HazMat, and necessary improvements on these policies. Another future research is to develop a multi-criterion decision model for HazMat carriers to make best investments in reducing HazMat transport risks within their budgets. 


\section{CHAPTER 7 INTRODUCTION}

\section{INLAND WATERWAY SURVEY}

\subsection{BACKGROUND}

The inland waterways (IWW) networks consist of nearly 12,000 navigable miles which makes it vast in geographical area and able to carry high tonnages of goods (U.S Army Corps of Engineers, 2004). The direct access to large ports makes it very beneficial for carriers to use this mode of shipment. The inland waterways accounts for over 624 million tons of freight annually and create tremendous cost savings for U.S. agriculture sector (U.S Army Corps of Engineers, 2004). It also has a vital connection in energy production in the U.S. resulting in low energy cost. This makes it a crucial economy contributor, making up $14 \%$ of our intercity freight and is valued nearly $\$ 70$ billion [(U.S Army Corps of Engineers, 2004).

Geographically, the eastern half of the U.S. accounts for a great share of inland waterway system; nevertheless, all but nine of the fifty states have direct access to the waterway systems. Figures 15 and 16 illustrate the inland waterway distribution across the continent. The Mississippi river accounts for a large portion of this network, flowing from Minnesota down to the in Mississippi delta at the Gulf of Mexico. In fact, the Mississippi river flows across 10 state and have 12 tributaries in the Ohio River. This creates great opportunity transporting goods directly from ports to the market. 
The U.S Army Corps of Engineers (USACE) maintain intercostal waterways. This includes all commercially active dock sites and 237 dock chambers. These docks provide the infrastructure "stair step" system that reaches several inland ports. The docks are generally categorized by 3 different sizes expressed by their lengths. The sizes vary from 110 foot to 1200 foot; the larger the docks the more barge it can accommodate. The 1200 foot lock can accommodate a tow of 17 barges plus the tow boat, whereas, a 600 foot can pull in 8 barges plus the tow boat. The sizes of both the dock size and barge size can determine how much cargo can go through the docks.

Over $50 \%$ of the docks and dams operated by the USACE are within 600 foot and were built in the 1930's on the Mississippi, Illinois, and Tennessee Rivers. It was not until the 1960's the USACE begun to modernize the docks on the Ohio River. The updated docks are projected to cost $\$ 3.5$ billion and will be completed in over the next decade. Most of the funding from these infrastructure update project comes from fuel tax paid by inland towing companies. Therefore, in order for the USACE to continue to maintain and improve already existing docks and build new ones, they have to realize some form of growth in their business. Thus, promoting inland water way shipment is important to maintain this great infrastructure and resource. 


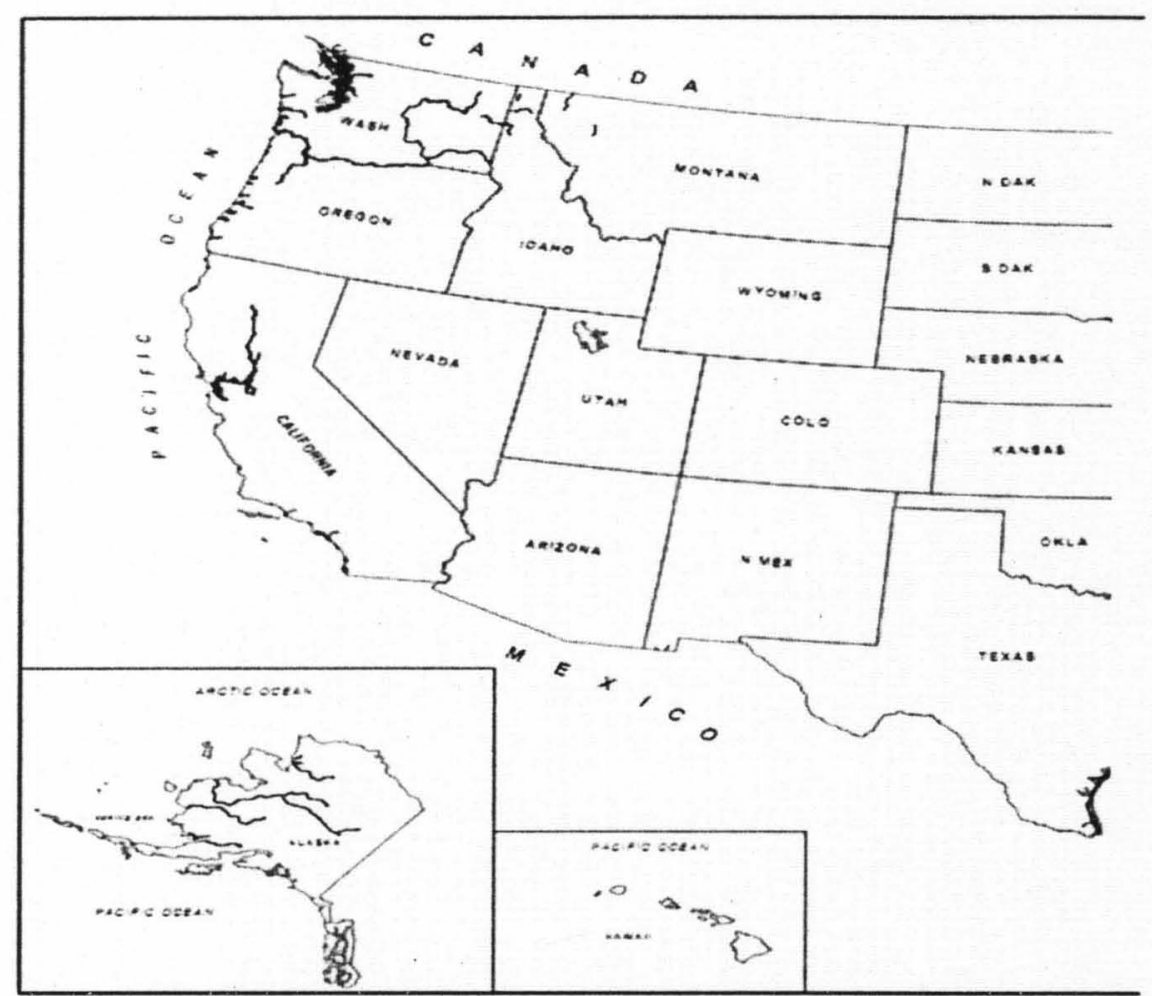

Figure 15 The western U.S Inland Waterway System

[Source: Waterborne Commerce of the Unites States, U.S Army Corps of Engineers, 2004, Figure $1-1]$.

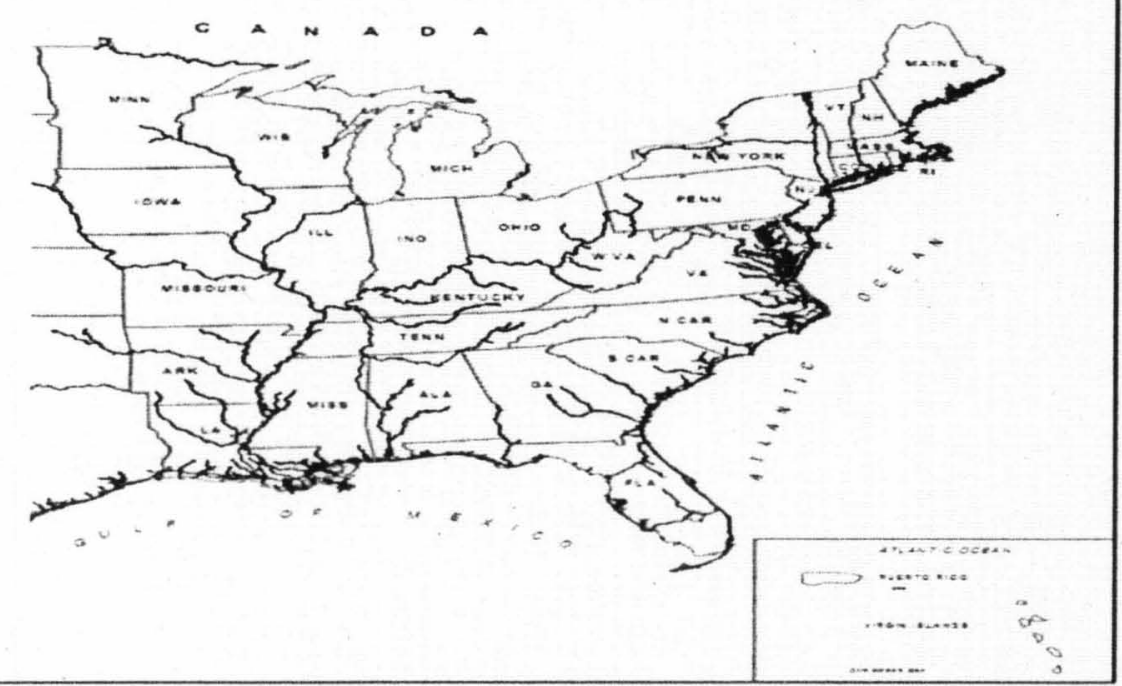

Figure 16 The eastern U.S Inland Waterways System

[Source: Waterborne Commerce of the Unites States, U.S Army Corps of Engineers, 2004, Figure $1-1]$. 
On the other hand, from the commodity flow view points, the petroleum industry accounts for about $36 \%$ as of 2003 for all goods transported along the U.S. inland and intercostal routes, making it the highest by volume. This is followed by coal/coke and sand/gravel/ stone aggregate by $21 \%$ and $13 \%$, respectively. Other common commodities via the inland waterways are Food/Farm (9\%), Chemical Products (7\%) and others (14\%). This is illustrated in Figure 17. When examining the shipment tonnage via the inland waterways; bulky and natural resource dominates the inland waterway traffic. Coal and coke products account for $28 \%$ of total tonnage and crude petroleum accounts for $25 \%$ of total tonnage. These two commodities accounts for more than $50 \%$ of the total volume shipped via inland waterway. Other commodities by tonnage include food/farm (14\%), sand/gravel/stone aggregates $(14 \%)$ and chemical products $(8 \%)$. Also iron ore, manufacture equipment and manufactured goods for about 11\% combined (U.S Army Corps of Engineers, 2003).

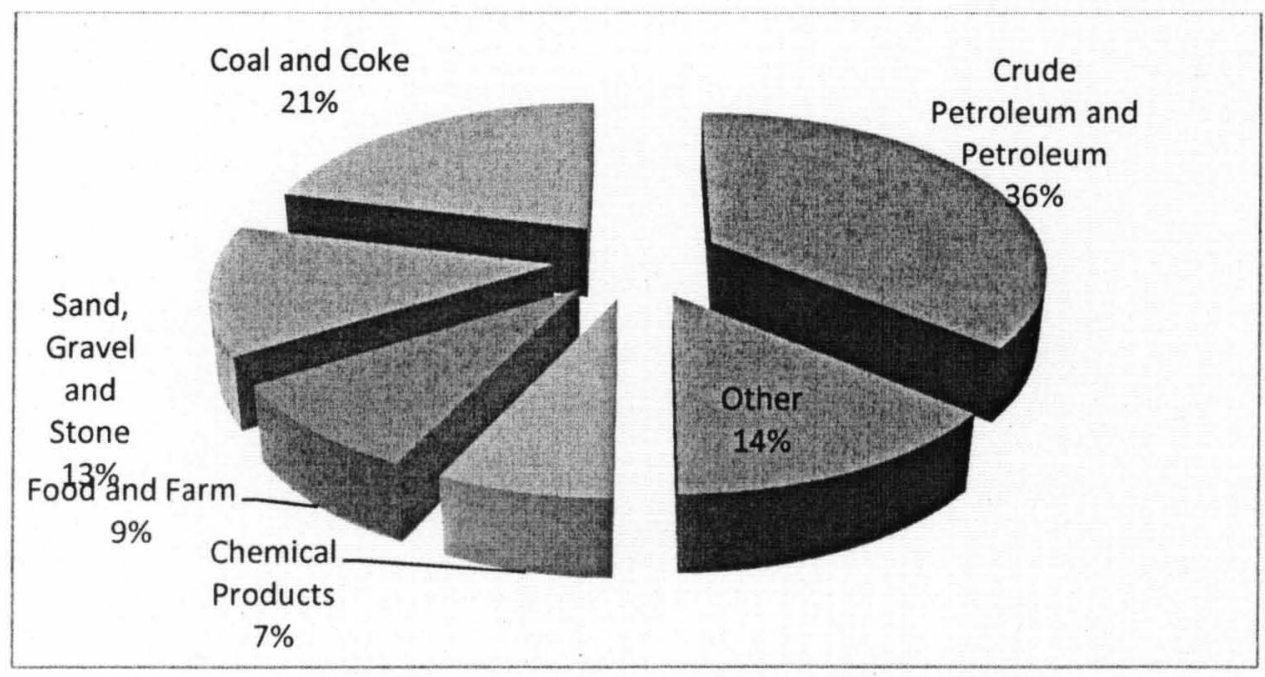

Figure 17 - Total U.S Waterways Traffic by Commodity, 2005

(Source: U.S. Army Corps of Engineers 2003: Water Commerce of the united State 2005, Commodities 2-11.) 
The inland waterway has not seen tremendous growth in the last decade. This may be due to more use of other transportation modes such as trucks and railways. As the demand for transporting commodities continues to increase, the use of trucks and railway thereby increases congestion on our highways and inner-city roads.

Barges are used to haul bulk/low-value items at a relatively low cost. A typical barge measure 195 by 35 feet and can carry up to 1,500 tons of cargo. It will take only 1 barge to carry 1,750 short tons of dry cargo; for the same amount of tons, 16 rail cars and 70 trucks will be required. One barge load of gasoline, for example, would require 46 rail cars or 144 trucks to move the same amount to market. In regions that are served by waterways transportation, today's gasoline costs might be even higher, if not for the lower cost waterway alternative.

Also, the ability to tow several barges together allows for more volume to be shipped at the same time. In other words, fifteen barge towed together is equivalent to 216 Rail Cars (6 Locomotives) and 1,050 Trucks.

There are several advantages of using for inland waterway for shipping commodities and they are as follows:

- Transportation freight by water is the most energy-efficient source: Barges move approximately 1 ton of cargo 576 miles per gallon of fuel. Whereas, rail cars move the ton of cargo 413 miles and trucks only 155 miles. 
- Inland barges produce less carbon dioxide: For every million ton-miles, barge will produce 19.3 tons of $\mathrm{CO} 2$. While Rail and Trucks for same ton-miles will produce 25.9 and 71.5 , respectively.

- Inland waterways transport generates fewer emissions than rail or truck per tonmile, i.e., barge transportation generates the lowest emissions particulates matter.

- Inland waterways transport moves hazardous materials safely: Spills are low for barge (3.6 gallons per one million ton-miles) in comparison to truck (6.06 gallons per one million ton-miles) and rail cars (3.86 gallons per one million tonmiles).

- Inland waterways transport has a low injury record compared to rail or truck: For every one injury involving barge transportation, there are 125.2 injuries related to rail and 2,171.5 truck related injuries.

- Inland waterways transport has a low fatality compared to rail or truck. For every one fatality involving barge transportation, there are 22.7 fatalities related to rail and 155 truck related fatalities.

In Addition to all these benefits the cost savings associated with barges makes them very competitive as well. According to the American Society of Civil Engineers (ASCE), the average cost of moving cargo by barge in the Port of Pittsburgh district ranges between $\$ .005$ and $\$ .01$ per ton mile of cargo moved, compared to $\$ .05$ for rail and $\$ .10$ for trucking. Even with all this benefits Inland waterways still remains under-utilized by many potential customers. 


\subsection{RESEARCH OBJECTIVE}

The objective our research is to understand the factors that manufacturers consider in choosing what mode of transportation for their commodity. Also we wanted to propose an incentive that will either encourage participants who are currently using the mode for shipment to increase the volume transported via IWW or stimulate those who are not currently using IWW to consider shipping via IWW.

The remaining of this part of the thesis is organized as follows. Chapter 8 discusses the methodology we use to design the questionnaire. Chapter 9 describes the method of collecting data from manufacturers. Chapter 10 analyzes the results from the survey, and finally Chapter 11 offers conclusions and recommendations. 


\section{CHAPTER 8 METHODOLOGY}

To meet the aforementioned objectives, we created a survey for manufacturers to better understand the decision making in selecting transportation mode based on several factors we think are important.

\section{SURVEY DESIGN}

The survey was divided into two sections; the first section of the survey was for those currently shipping via IWW and the second section was for those not currently shipping via IWW.

\section{Research Questions}

The following questions guided the survey for companies currently shipping IWW:

- What is the company's basic profile? (Company name, company geographical location, number of employees, their number of outbound shipment per year).

- What is the commodity status? (Commodity manufactured their percentage allocation of each mode of transportation, their top three shipment destinations, average weight per shipment via IWW).

- Financial status and incentive proposed? (how do cost factor in their shipment mode decision, their current savings from using IWW, will cost of gas push them to increase volume shipped via IWW, will the introduction of an incentive (Cap-and-Trade policy) also encourage more volume shipped via (WW) 
The following questions guided the survey for companies not currently shipping via IWW:

- What is the companies' basic profile? (Company name, company geographical location, number of employees, their number of outbound shipment per year)

- What is the commodity status (commodity manufactured, their percentage allocation of each mode of transportation)

- Financial status and incentive proposed? (how much will cost of gas increase before considering shipping via IWW, will the introduction of an incentive (Capand-Trade policy) also encourage shipping via IWW) 


\section{CHAPTER 9 DATA COLLECTION}

The respondents of this survey were manufacturers who are currently using IWW to ship commodities and currently using other transportation modes to ship their products other than IWW. There were no restrictions on sizes or locations of the participants. This will allow us to see how sizes of the participants relate to their capabilities. Also, having a mixture of companies that currently use and do not use IWW, will give more insights to why some choose to use it or otherwise. Although, conscious effort was made to only involve company that was relatively close to inland waters. All response were voluntary obtain and a total of 26 usable surveys was received from participants.

Respondents were initially identified from two leading industry website www.industryweek.com and www.waterwayscouncil.org. The first online source lists leading industry manufacturers, and allows users to filter out companies based on user request. Respondents were selected based on the commodity they produced and the feasibility of this commodity to be transported via IWW. The later online resource is maintained to the waterways council, Inc., whose primary goal is to promote and create awareness about the benefits of using IWW. Using this source, companies that currently use IWW to transport their commodity were identified.

Initial phone calls were made to potential participants to identify a contact person and see if they were interested in participating. Respondents were given three different options on how to complete the survey, depending which was more suitable for them. Surveys 
were distributed using an online survey company called Survey Monkey. Of the 27 responses only 1 had information that was usable from the online survey. A total of 2 responses were attained by mail and the remaining 24 by phone. 


\section{CHAPTER 10 SURVEY RESULT AND DATA ANALYSIS}

The survey data were input into an EXCEL spreadsheet for analysis. Using EXCEL as a centralized location for all survey responses collected over the phone, internet and hard copy, we were able to identify duplicate response.

\subsection{COMPANY INFORMATION}

A total of twenty-seven companies participated in this survey, among which 24 responses were collected by phone calls, 1 response from the internet and 2 was collected via mail. The responses all indicate that not all participants currently incorporate inland waterways transportation into their shipment means, 9 of the 24 indicate that they currently are using inland waterway and 15 indicated that they do not use this mode. Table 1 shows the companies that indicated that they currently use inland water ways as a mode to ship their commodity. It also shows the number of employee, their location and the percentage usage of IWW relative to other modes. The company size ranges from 11 employees to 800 employees and their geographical distribution stretches from the Missouri river to Ohio river; 6 (Westchester-OH, Lexington-KY, Pittsburg-PA, Louisville-KY, MillwoodWV) of our participants can be located along the Ohio river, 1 (Nashville-TN, Fort Smith-AK) is along the Mississippi river, 1 (Jefferson city-MO) is along the Missouri river and lastly 2 (Columbia - IL, Davenport-IA) is along the Illinois river. From the table, it can also been seen that with the exception of 1 company whose main business is mostly IWW freight, all others use a mixture of different modes of transportation including inland waterway, railway, and truck. 
Companies that do not currently use IWW for their commodity shipment is compiled in table 5. Their company sizes range from 3 employees to 1000 employees. Their geographical distribution is also well spread out the U.S and all except three which are located in New Mexico, Oregon and North Dakota respectively are all in states that has some form of inland water. Most companies in the categories expressed why they do not currently use IWW or what incentives will motivate them to explore the shipment mode. More discussion for this decision is discussed in the coming section.

Table 4 Companies that currently ship via Inland waterways

\begin{tabular}{|c|c|c|}
\hline \multicolumn{3}{|c|}{ Companies that Currently ship via Inland waterways } \\
\hline Number of employees & Company Location & Percentage Usage \\
\hline 200 & Westchester, OH & $60 \mathrm{~T}, 53 \mathrm{R}, 5 \mathrm{~W}$ \\
\hline 50 & Jefferson City, MO & $95 \mathrm{~T}, 5 \mathrm{~W}$ \\
\hline 800 & Nashville, TN & $100 \mathrm{~W}$ \\
\hline 11 & Lexington, $\mathrm{KY}$ & $1.5 \mathrm{~T}, 98 \mathrm{R}, 0.5 \mathrm{~W}$ \\
\hline 200 & Pittsburg, PA & $75 \mathrm{~T}, 10 \mathrm{R}, 15 \mathrm{~W}$ \\
\hline 50 & Louisville, $\mathrm{KY}$ & $60 \mathrm{~T}, 30 \mathrm{R}, 10 \mathrm{~W}$ \\
\hline 75 & Columbia, IL & $4.5 \mathrm{~T}, 0.5 \mathrm{R}, 95 \mathrm{~W}$ \\
\hline 17 & Millwood, WV & $90 \mathrm{~T}, 10 \mathrm{~W}$ \\
\hline 750 & Lexington, KY & $15 \mathrm{~T}, 80 \mathrm{R}, 5 \mathrm{~W}$ \\
\hline 250 & Fort Smith, AK & T60, W30, R10 \\
\hline 25 & Old Monroe, MO & $100 \mathrm{~W}$ \\
\hline $100+$ & Davenport, IA & T70, W10, R20 \\
\hline
\end{tabular}

Table 5 Companies that do not currently ship via Inland waterways

\begin{tabular}{|l|l|}
\hline \multicolumn{2}{|c|}{ Companies that Do not Currently ship via Inland waterways } \\
\hline Number of employees & Company Location \\
\hline 38 & Barbourville, WV \\
\hline 200 & Pittsburg, PA \\
\hline $15-20$ & Cleveland, OH \\
\hline 12 & Farmington, NM \\
\hline 15 & Mississauga, ON \\
\hline $3-4$ at each location & Southfield, MI \\
\hline 200 & Grammer, IN \\
\hline
\end{tabular}




\begin{tabular}{|l|l|} 
N/A & Douglas, WY \\
\hline 4 & Bensenville, IL \\
\hline 30 & Fort Worth, TX \\
\hline 1000 & Tallahassee, FL \\
\hline 15 & Sioux City, IA \\
\hline 50 & Portland, OR \\
\hline $100+$ & Kenai, AK \\
\hline 126 & Rapid City, SD \\
\hline
\end{tabular}

**Note: $\mathrm{T}$ indicates Truck, $\mathrm{R}$ indicates Railroads and $\mathrm{W}$ indicates Waterways

\subsection{COMMODITY FLOW}

In this part of the survey we aim to find out what commodities are currently shipped by these companies, the frequency of their outbound shipment per year and the average weight per shipment shipped via IWW for those company that currently use this mode. The results to these questions are discussed as follows.

Figure 18 illustrate the commodity distribution for companies that currently uses a percentage of IWW for shipment. 67 percent of respondents report that they ship aggregate product making it the number one commodity shipped. Coal and Coke products are the second most shipped commodity via IWW by our 33 percent of respondents. This is followed by Iron \& Steel $(22 \%)$, Chemical (11\%), Crude Petroleum \& Petroleum $(0 \%)$, and Timber or others $(0 \%)$. This does not represent the general percentage of each commodity relative to the entire volume of commodities shipped via IWW as shown in Figure 17. Our result only reflects the commodities shipped by the respondents. 


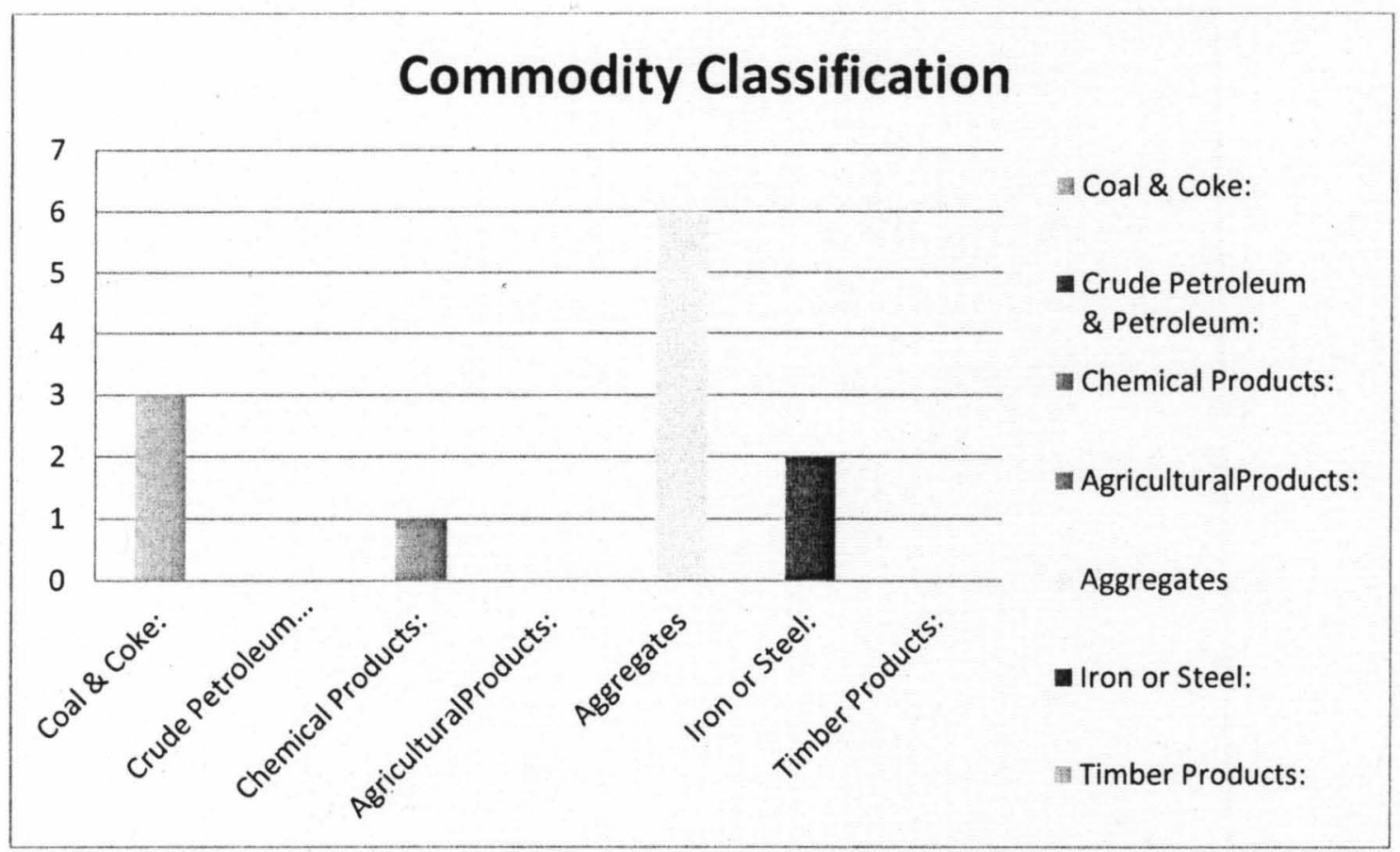

Figure 18: Company currently using IWW

In addition to what commodities each company shipped via IWW, question 5 of our survey asked participants what the total number of outbound shipment per year was. Although, there is a lack of exact numbers of shipment per year, all companies indicated that they were in the 1000 's. It can be inferred that there is no correlation between the size of the company and their number of outbound shipment.

Question 10 asked what their average weights per shipment were; Participants indicated a range of 1000 tons to 1750 tons per shipment, again we observed there is no correlation between the sizes of the companies, commodity to how much they shipped in weight. We can conclude that most commodities shipped via IWW are in bulk or very heavy items. Also, all respondents indicated that they haven't increased the volume shipped via IWW any time recently. 
Also, 5 of the 11 respondents that indicated that they were already shipping via IWW experienced a savings, which ranged from 6 percent to 60 percent by transporting their commodities via IWW. This is a validation that the cost saving for using IWW can be very significant for a company profit margin.

Figure 19 represents the commodities and their distribution for companies that do not currently use IWW as a shipping mode. Crude petroleum and chemical products were indicated to be the most commodity associated with companies that do not use IWW currently, with both having 36 percent. However, 80 percent of Crude petroleum also shipped chemical products. This did not come as a surprise, because there are several chemicals that are by-products of Crude oil. The second highest commodity was Iron \& Steel with 22 percent of the respondents shipping this commodity; this result shows a close statistics with the percentage of respondents currently using IWW which also had a

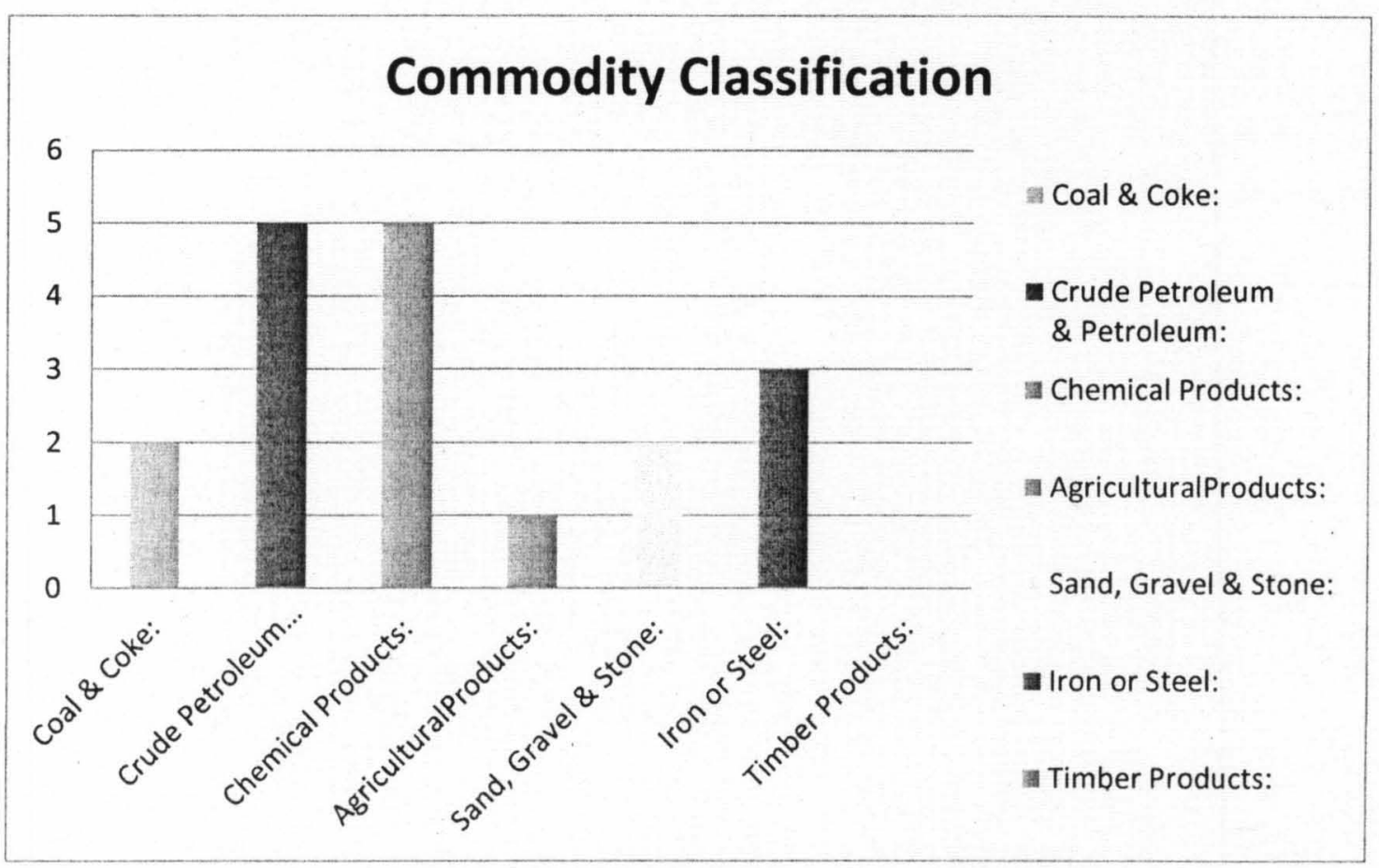

Figure 19: Company not currently using IWW 
22 percent share in this category. Although, this does not reflect the entire iron \& steel industrial, it shows that different factors can decide what shipment mode is best suitable for a company to explore. These three categories are followed by Coal \& Coke (14\%), Aggregates (14\%), Agriculture (7.1\%) and Timber \& other (0\%). Again, we observed that timber takes a $0 \%$ share in these categories; this is not typically the case according to the port of Louisiana, timber accounts for a percentage volume of commodity that is processed yearly.

However, to further understand the decision factor for why these companies choose either to use IWW for their shipping fulfillment or why they do not use this mode, we ask if cost was a major factor in their decision making and were to rank this factor. Based on a scale from 1 to 5 and with 1 being "extremely important" and 5 being "not very important" participants ranked accordingly and the results is as follows.

Table 6 and Table 7 indicate the response for cost as a transportation decision factor for those companies currently using IWW and those not currently using IWW respectively; and it can be observed that cost as a transportation factor is very subjective to companies cost of operations. This is very surprising because the respondents see cost as either "somewhat unimportant" or "not important at all". This view is shared by 10 respondents from the 27 total respondents that participated in this survey. This is interesting because we assumed that since these are companies whose goal is to have wide profit margin, cost will be very important. On the other hand, this suggests that there are several other factors that might also account for the transportation decisions by these companies. 
Table 6 Company that currently ship via Inland waterways cost factor

\begin{tabular}{|c|c|}
\hline \multicolumn{2}{|c|}{ Cost as Transportation Decision Factor } \\
\hline Extremely Important (1) & 5 \\
\hline Somewhat important (2) & 1 \\
\hline Either way (3) & 0 \\
\hline Somewhat unimportant (4) & 1 \\
\hline Not important at all (5) & 4 \\
\hline
\end{tabular}

Table 7 Company that do currently ship via Inland waterways cost factor

\begin{tabular}{|c|c|}
\hline \multicolumn{2}{|c|}{ Cost as Transportation Decision Factor } \\
\hline Extremely Important (1) & 5 \\
\hline Somewhat important (2) & 1 \\
\hline Either way (3) & 1 \\
\hline Somewhat unimportant (4) & 1 \\
\hline Not important at all (5) & 4 \\
\hline
\end{tabular}

All participants were asked the question of government incentive for attracting more use of IWW shipment called Cap-and -Trade. Firstly, we wanted to know if they have any knowledge of the incentive, and secondly, if that could be an attractive incentive for either increasing volume shipped via IWW or exploring the IWW option.

When respondents were asked if they had any knowledge of the Cap-and Trade policy, only 3 of the 27 respondents indicated they had some knowledge of this incentive program by the Federal government. The idea of this incentive did not convince any of the survey participants that were currently not using IWW to even consider the option.

In addition, to this incentive, companies that currently do not use inland waterway were asked how expensive would gas cost be to influence their consideration of switching to IWW from other shipping modes, only 1 participant indicated gas price will have to 
increase to an astonishing $\$ 9$ per gallon before considering IWW, all other respondents said that fuel price isn't even a consideration.

The last part of the survey was for companies that currently do not use inland waterway to rank 6 different factors, including average lead time, cost, and tracking ability, reliability, environmental factors and convenience. These factors have been identified to affect the decision making procedure for which mode of shipment companies will use. The figures below represent each factor and are discussed as follows.

The average lead time is the time from the moment a customer places an order to the time it gets to the customers. It can also be defined in the different context depending on the area of operations. This is a very important factor and can in a Just-in-Time age, getting your product to customers in the shortest possible time can be crucial. The average lead time (Figure 5) ranked from a scale of 1 (most important) to 6 (least important) by respondents. At $20 \%$ and $40 \%$ respondents indicated that average lead time was either somewhat important or less important respectively. This does come as a surprise, especially because of the implication of what a poor lead time can do to company; on the other hand, because highway transportation and railway are very reliable, suppliers can respond to customers' demands quicker. 


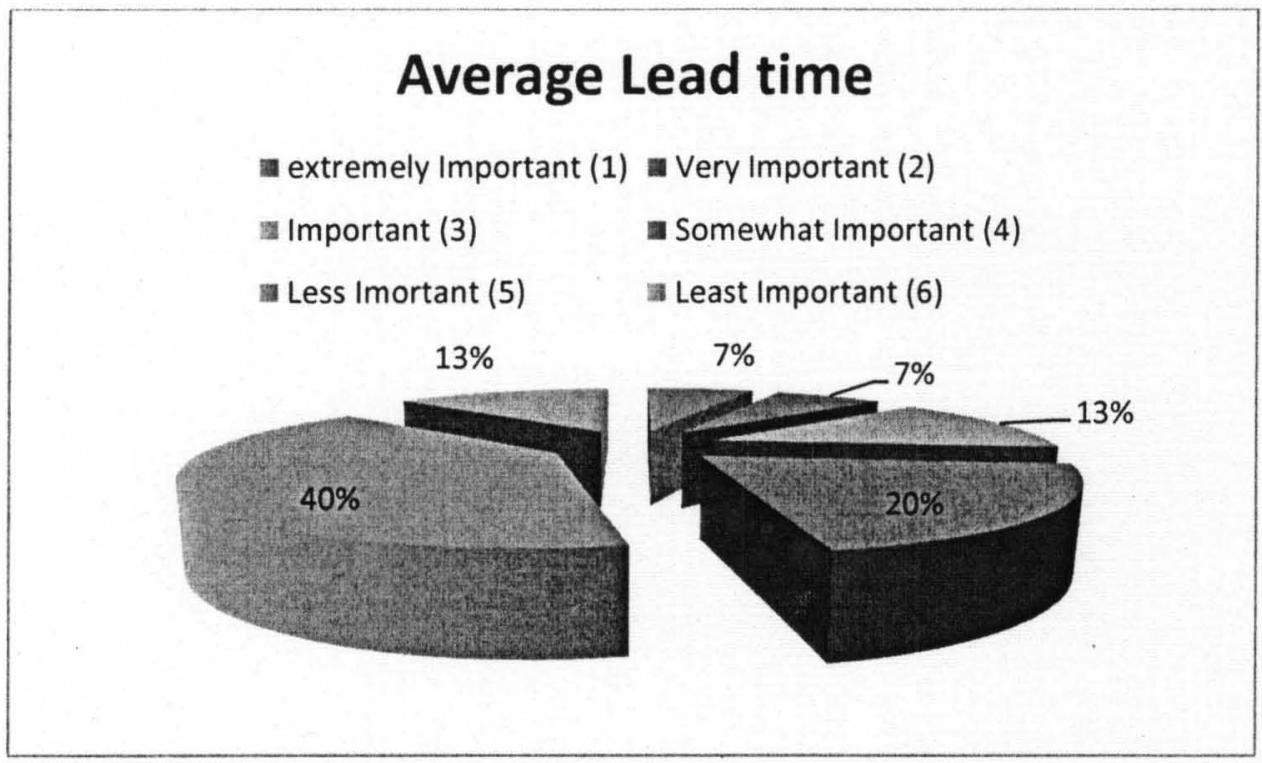

Figure 20: Average Lead Time

The second factor for comparison is cost. The pie chart indicates that at $33 \%$ and $27 \%$ respondents consider cost as an extremely important or very important factor. Although, this might seem contrary to a similar question asked earlier, keep in mind that is response is only for those not currently using IWW as a transportation mode. 


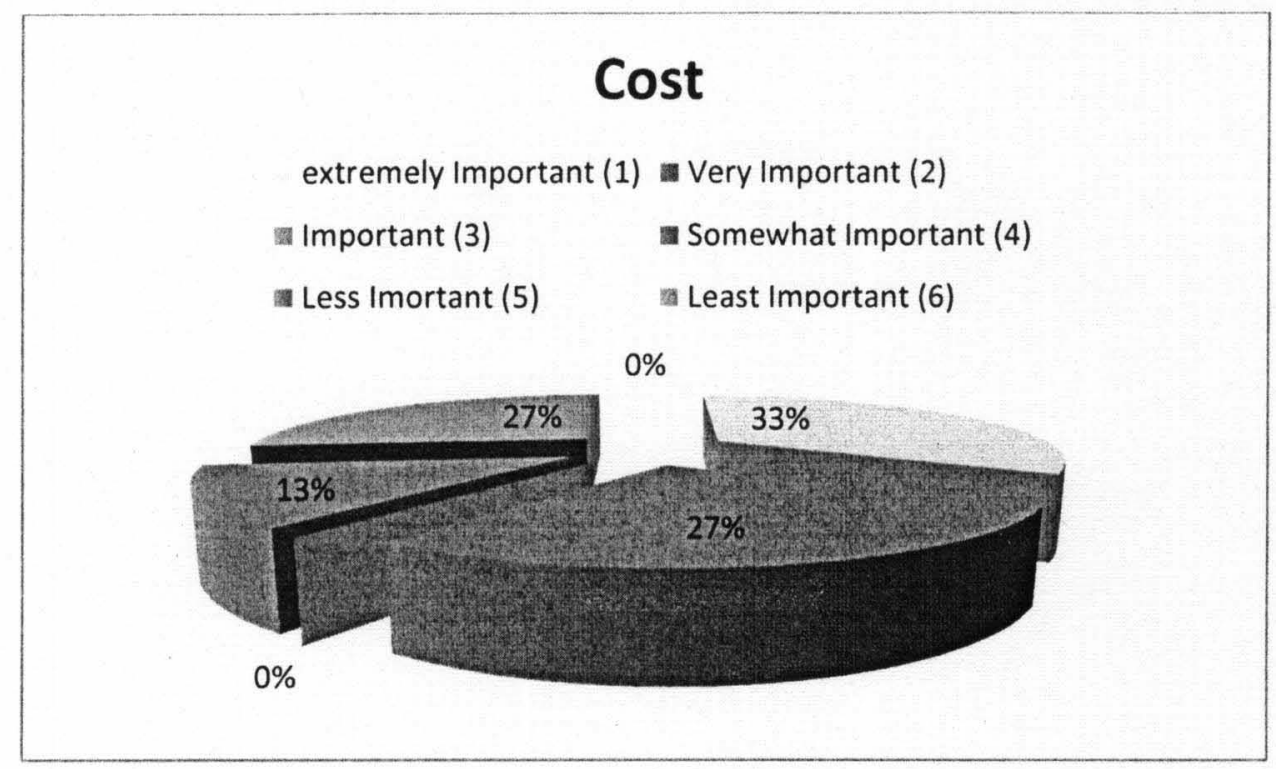

Figure 21: Cost

Tracking capability was seen to be somewhat important $(36 \%)$ and important $(29 \%)$ making them the top two options chosen by respondents. This might not be as important to supplier as it is to customers.

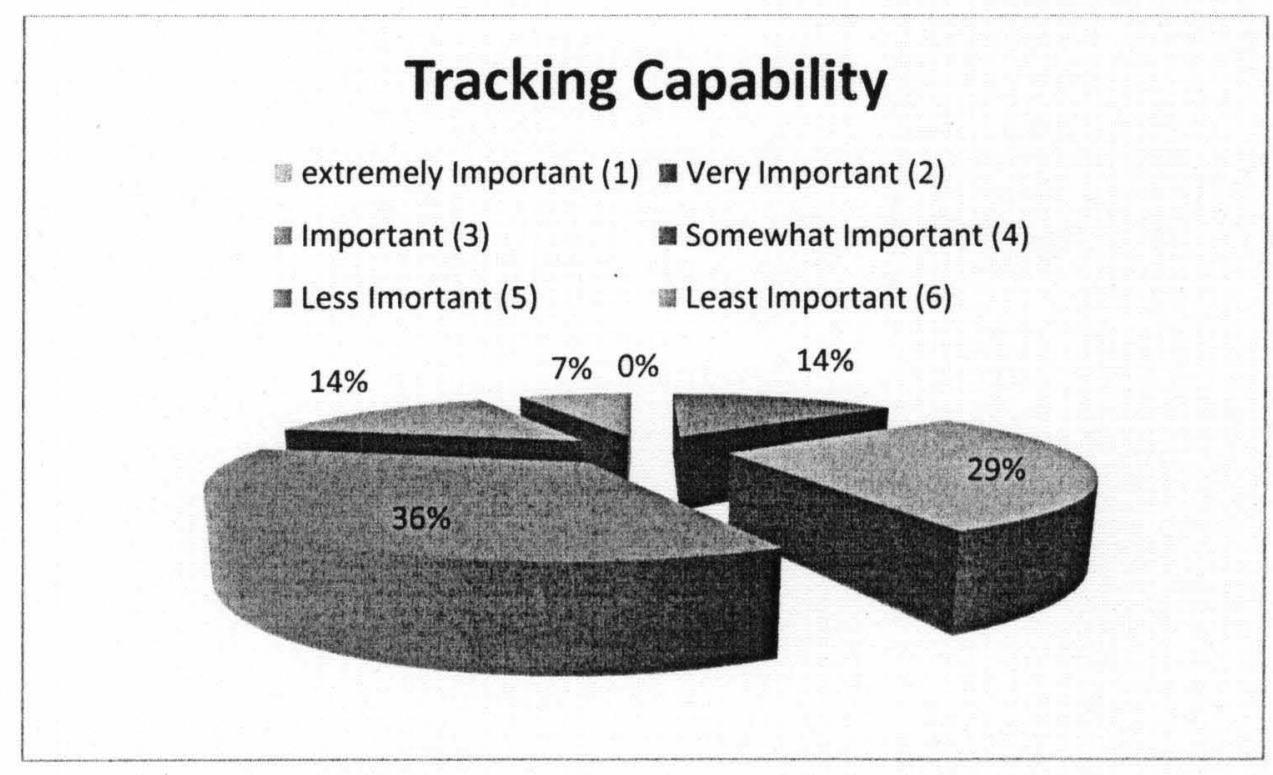

Figure 22: Tracking Capability

The reliability or predictability of lead time is also a factor we considered that might be important for carriers when deciding for mode to use, as it guarantees that suppliers can 
provide customer with reliable time frame of when their products will be received. Figure 23 shows the importance of this factor when deciding their transportation strategy. 27 percent of respondent choose this factors as less important, while 20 percent choose it to be somewhat important and $27 \%$ also thought of it to be least important. Also, at $0 \%$ no respondents thought it was an extremely important factor and this answers support the first factor (Average lead time).

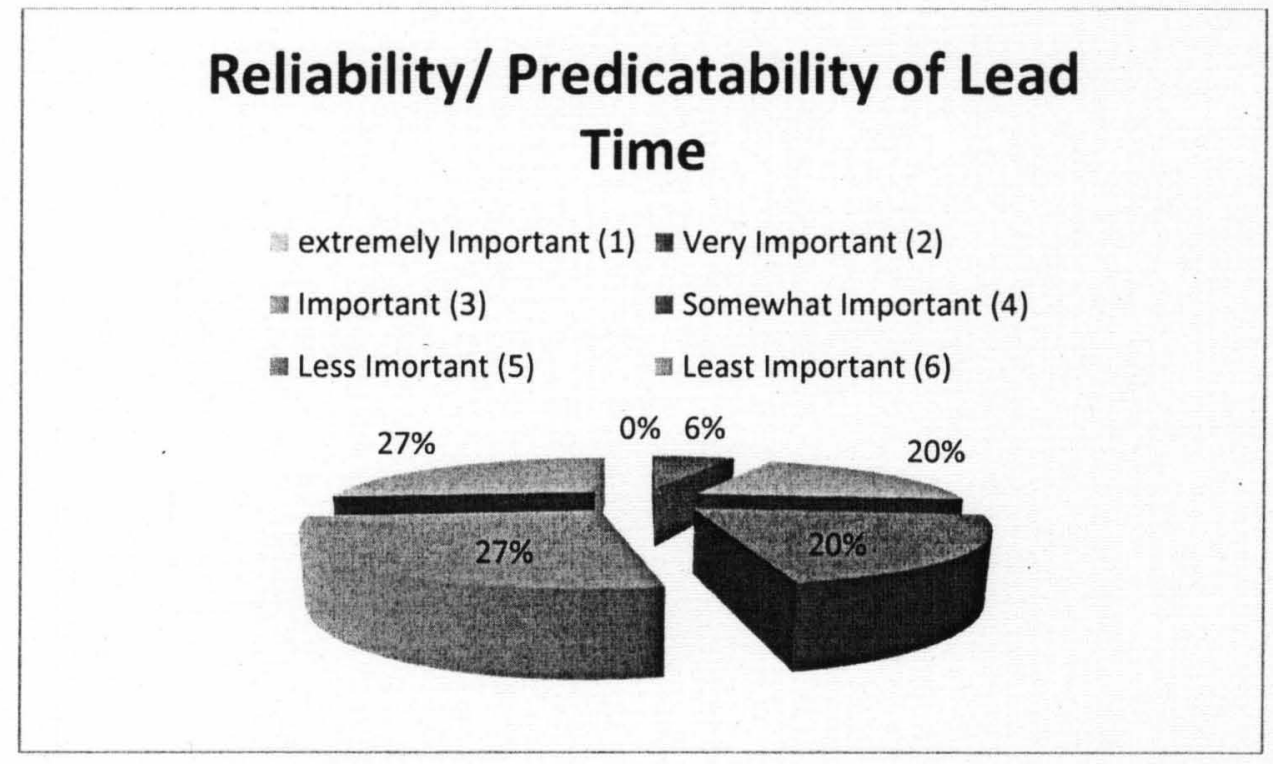

Figure 23: Reliability/Predictability of lead time

Environmental factor (Figure 24) was proposed to participants and if that was a factor they considered when making transportation decision. From the observation of the data, the might be a considerable factor, but cost is more important to this stakeholders. 


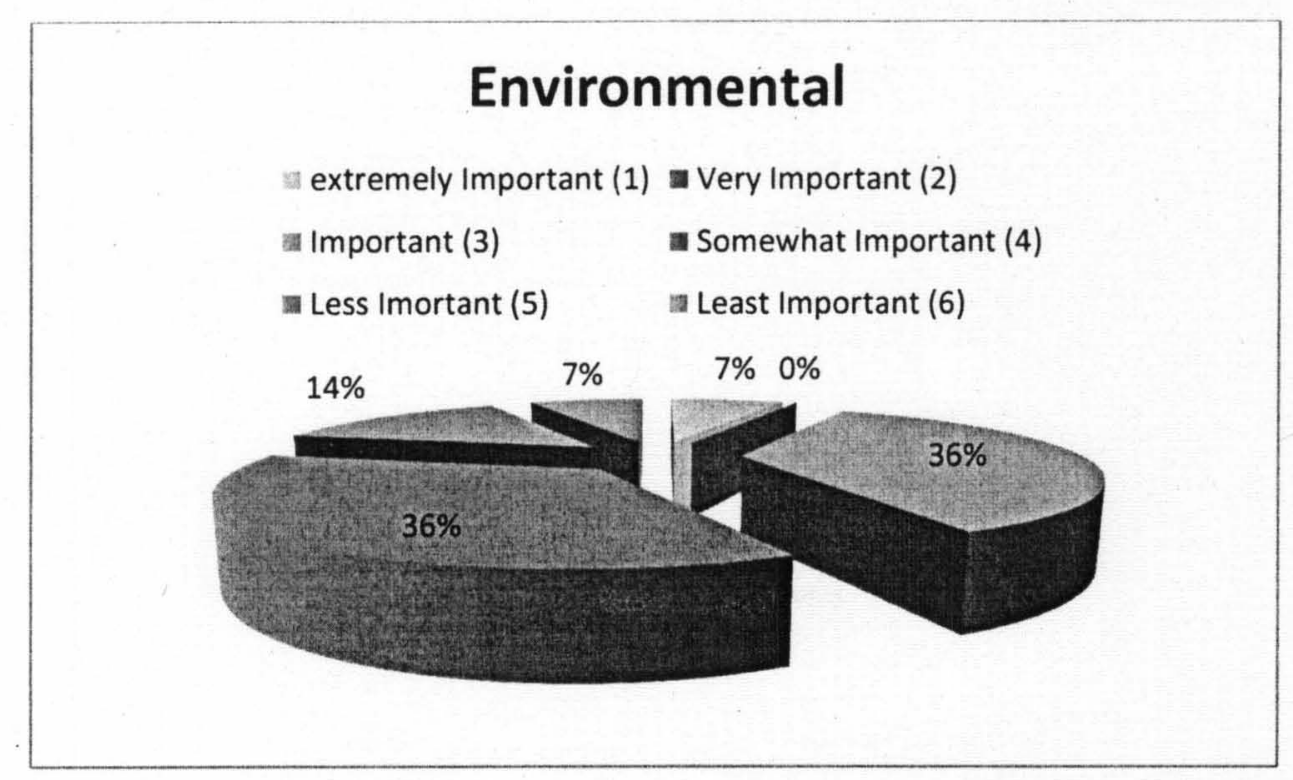

Figure 24: Environmental Factors

Convenience is not considered to be either extremely important or least important. $20 \%$ think it is very important, while the others choose otherwise. This data, in our opinion, is not realistic; most of the respondent in this categories mainly transport their commodities through roads and that makes for a more flexible in terms of route options and convenience. We believe that respondents may not have given much thought to this factor in particular. 


\section{Convenience}

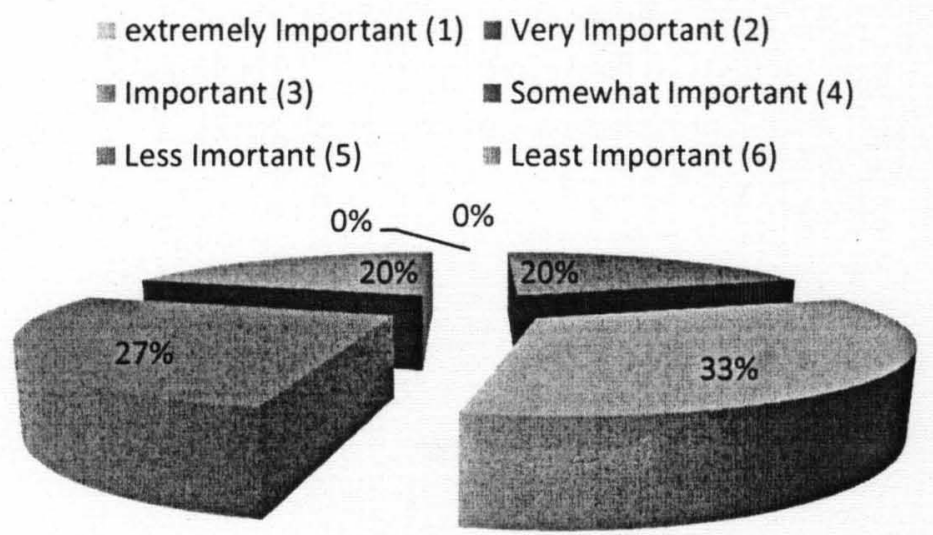

Figure 25: Convenience

Overall comparison shows that for those who are not using IWW, Cost is the no. 1 consideration. This is followed by convenience; and the reliability/predictability of lead time is observed to have a lesser value compared to the other factors.

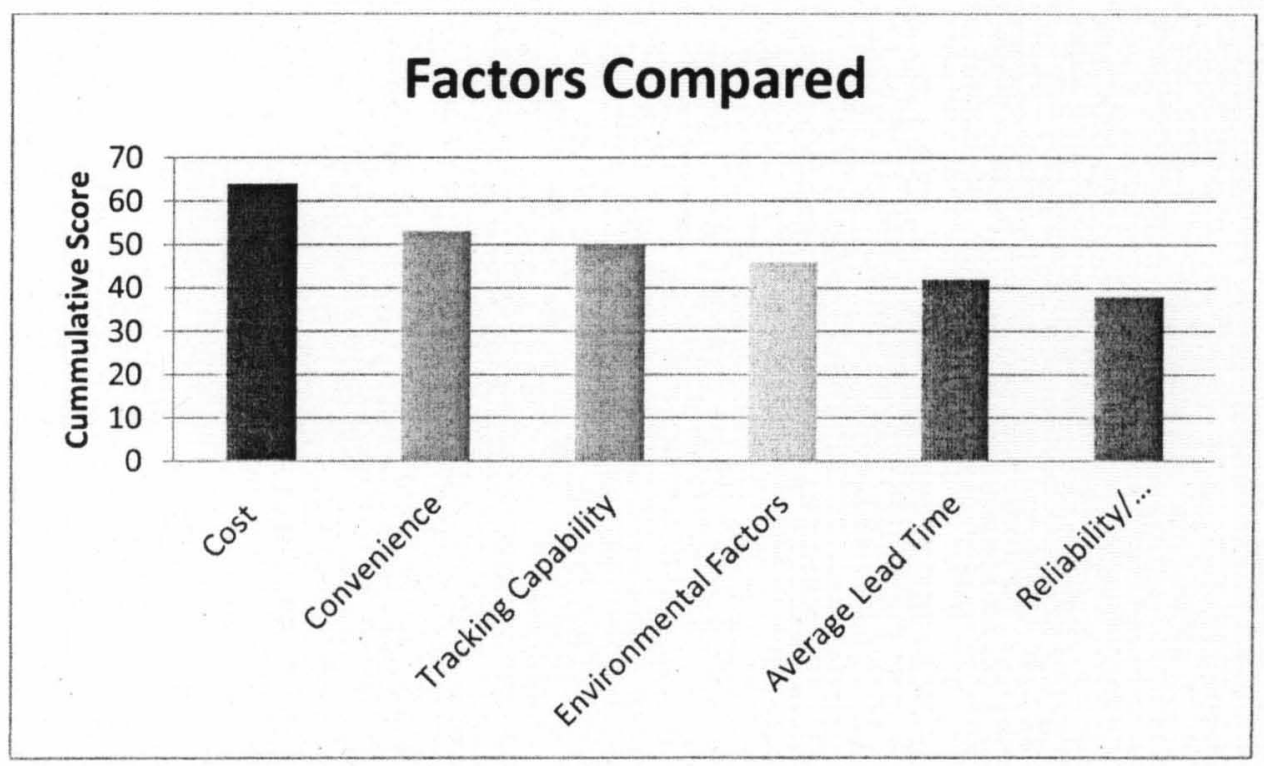

Figure 26: Overall Comparison 
The end of the survey Respondents were given the opportunity to make additional comments. Following are some of the comments provided:

- "Potentially interested in using inland waterways in the future"

- "Cannot sell that way, not feasible for ready mix concrete"

- "Location is not beneficial to use inland waterway mode"

- "customers pays for shipping, so cost is not a variable"

- "customer location and geography is a factor"

- "Waterway doesn't work. Shorter distances, for feasible to use roadways"

- "Not feasible, not everyone is equipped to receive via waterways"

- "Overall Security"

- "Trucking Comp./Inland waterways are their competitor 


\section{CHAPTER 11 CONCLUSIONS AND RECOMMENDATION}

The inland waterway system as intermodal freight system is critical to boosting the U.S economy and the potential to increase the volume of products shipped via this system is very feasible. Its competitive pricing and high volume capability should make it an attractive mode for manufacturer who has the access to this infrastructure. Also, the low carbon footprint of inland marine vehicle is very low compared to trucks and train can create incentives for manufacturer who uses the mode one way or the other. As a result of the continuous decline of the inland marine freight sector in the last decades understanding manufacturer needs is crucial for us to start seeing growth again.

The objective of this research was to see what factors can stimulate this growth. The data analysis of the survey yields the following observation. First, "cost" is seen to be the most important factor by manufacturer both those using and not using in deciding what mode of transportation to use for their shipment. Seventy-two percent of those currently using inland waterways and fifty percent those not currently using inland waterways thinks that "cost" is either "extremely important" or "somewhat important" when they are deciding what mode of transportation to ship with. One of the participants did not consider cost as a factor for shipping their commodity, because that was passed on to customer and using inland waterway to save cost did not make a significant difference to their operating cost. Another company indicated that they shipped all their coal to their own power plant; therefore, cost of shipping is already factored into their operations cost. Secondly, the cap-and-trade incentive proposed to the participant did not seem to sway 
their decision on whether to increase volume shipped via IWW or explore IWW as mode for shipment. One of the participants who currently use a percentage IWW to ship its product indicated that they already ship as much volume as feasible via IWW. Thirdly, only one participant amongst those not currently using IWW indicated that the price of gasoline will have to increase to $\$ 9$ before even considering this mode of transportation. Finally, when the six factors that were proposed to participants who are not currently using IWW were compared, participants' ranking again showed that cost was the most important factor, followed by convenience.

The above conclusions lead to several recommendations. First is introducing value reorientation programs for both manufacturers and consumer; educating them about the environmental impact of greenhouse emission. Second, manufacturers can forecast customers demand, thereby having enough lead time for ship to regular customer; by doing this Inland waterway can become a suitable option. Third, the U.S Army Corps of Engineers should act as solicitors to manufacturer, making them aware of cost saving opportunities that come from using this mode. Fourth, more financial investment toward infrastructure may help boost the use of inland waterways for shipping cargo. The construction of more locks and dams within city area will make it more convenient for manufacturers to send and pick up their cargo. Finally, there is currently no opportunity for tracking cargo on inland waterway. Therefore, developing efficient tracking technologies and communication systems should give inland waterway more opportunity for growth. 


\section{LIST OF REFERENCES}

1. "Hazardous Materials Safety and Security Technology Field Operational Test," Volume II : Evaluation Final Report Synthesis. Wasington, D.C: Federal Motor Carrier Safety Administration, U.S. DOT, 2004.

2. Transportation Security Administration Mission Statement, http://www.tsa.gov/who_we are/mission.shtm (accessed November 1, 2011).

3. Transportation Security Administration. "DHS Traveler Redress Inquiry Program (DHS TRIP)." http://www.tsa .gov/traveler/customer/redress/index.shtm (accessed November 1, 2011).

4. "Highway Security- Sensitive Material (HSSM) Security Action Items (SAIs)." http://www.tsa.gov/what_we do/tsnm/highway/hssm_sai.shtm (accessed November 1, 2011).

5. "Enhancing Security of Hazardous Materials Shipments Against Acts of Terrorism or Sabotage Using RSPA's Risk Management Self-Evaluation Framework (RMSEF)." http://www.tsa.gov/assets/pdf/rmsef.pdf (accessed November 12, 2011)

6. Federal Motor Carrier Security Administration, Safety and Security http://www.fincsa.dot.gov/safety-security/safety-security.htm (accessed November 12, 2011)

7. "Regulation." http://www.fmcsa.dot.gov/safetysecurity/HazMat/complyhmregs.htm\#hms (accessed November 12, 2011

8. "HazMatTransportation"http://www.fmcsa.dot.gov/safetysecurity/HazMat/fot/fin alrpt/chap2.htm (accessed November 12, 2011 )

9. "Mitigation Definition."

http://www.fema.gov/government/mitigation.shtm(accessed November 12, 2011 ) 
10. "HazMat Permit." http://www. fmcsa.dot.gov/safety-

security/HazMat/FederalRegister-OOS-Calculation-Policies.pdf (accessed November 13, 2011)

11. "Vehicle disabling Sytem."http://www.fincsa.dot.gov/facts-research/systemstechnology/product-guides/vehicle-disabling.htm (accessed November 12, 2011 )

12. Mineta Transportation Institute, Potential Terrorist uses of Highway-Borne Hazardous Material http://transweb.sjsu.edu/mtiportal/research/publications/documents/2981 Terrorist $\% 20 \mathrm{U}$ ses_011410.pdf (accessed October 12, 2011 )

13. U.S. Army Corps of Engineers. (2004) Waterborne Commerce of the United States, Calendar Year 2004, Part 5 - National Summaries. Water Resources Support Center,Navigation Data Center, Alexandria, Virginia.

14. American Society for Civil Engineers (ASCE) Central PA, Lehigh Valley, Philadelphia,

Pittsburgh, 2006 Report Card for Pennsylvania's Infrastructure: May 2006. Available at: http://www.pareportcard.org/

15. U.S. Department of Transportation, Maritime Administration, Environmental Advantages of Inland Barge Transportation, August 1994 http://www.port.pittsburgh.pa.us/docs/eaibt.pdf (accessed November 26, 2011)

16. Institute of Trade and Transportation Studies, Pittsburgh, 2007 Inland Waterways and the Global Supply Chain, March 2007.

http://www.pianc.us/docs/SmartRivers_Main_Report.pdf (accessed November 26, 2011) 17. Bureau of Transportation Statistics. Commodity Flow Survey. Washington. Dec. 1999.United States Army Corps of Engineers. Navigation Data Center. The U.S. WaterwaySystem-Transportation Facts. Alexandria, VA. Dec. 2002.

18. National Waterways Foundation, Waterways: Working for America, 2008 http://www.marad.dot.gov/documents/water works REV.pdf (accessed October 10, 2011)

19. Industry Weekly, The IndustryWeek U.S. 500 is IndustryWeek's report on the 500 largest publicly held U.S. manufacturing companies companies based on revenue, 2011 http://www.industryweek.com/research/us500/2011/iwus500rank.asp (accessed October 10,2011) 
APPENDIX A: Carrier and Manufacture Survey

1. Company Name

2. Where is your head office located?

3. How many employees does your company have?

4. Which best describes your organization?

- Government

○ Private

5. Does your company subcontract it logistics operations?

$\circ$ Yes

- No

6. Which type(s) of commodities does your company deal with their transportation? (please circle all that apply)

- Waste Disposal

- Private

- Pharmaceutical

$\circ$ Weapons

$\circ$ Others

7. What is the mode of transportation? (Please circle all that apply)

- Truck

- Water

- Railway 
- Intermodal: truck - water

- Intermodal: truck - railway

- Intermodal: water - truck - railway

8. What are the characteristics of the HAZMAT material transported? (Please circle all that apply)
$\circ \square$ Explosives
$\circ \square$ Gases
$\circ$ Flammable Liquid
$\circ \square$ Flammable Solid
$\circ \square$ Toxic (poison)
$\circ \square$ Radioactive material
$\circ \square$ Corrosive material
$\circ \square$ Oxidizer or Organic peroxide

9. Total Number of outbound shipments

10. What is/are the name(s) of the HAZMAT you transport?

11. What are the top 3 HAZMAT you transport?

a.

b.

c.

12. What is the average weight per shipment?

13. What is the average mile per shipment?

14. How many fleets of vehicle does your organization manage at a given time?

15. Are Background checks performed before hiring new drivers

$\circ$ Yes

○ No

16. What additional background check do you conduct on potential hires? 
- Criminal History

- Social Security number verification

- Immigration status verification

- Credit History

o Others

17. Do you currently have any security awareness training programs for employees/Drivers

- Yes

○ No

18. Do drivers have a long term designated truck

- Yes

$\circ \quad$ No

19. Which of the following risk are mostly associated with shipment?

- Theft/ Hijacking

- Sabotage

- Accident

- Vehicle Malfunction

- Leaks

- Terrorism

- Drivers

o Others

20. How is your supply chain protected?

- Careful planning of route

- Use of tracking gadgets

- standard security inspection policy and procedures

- Use of armed escort

- Following suggested TSA recommendations

- Standard alert protocols

- Standard reporting policy and procedures

- Two Drivers

- Driver(s) take only scheduled rest

- Continuous communication with all parties (e.g., law enforcement, highway emergency service, origin point, destipation boint. etc.)

- Others 
21. Which procedure from Question 21 will you say is most effective in reducing risk?

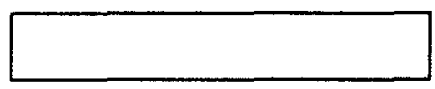

22. Which of the following technology do you currently use? (Please circle all that apply)
- RFID's
- Barcodes
- Satellite tracking (GPS)
- Electronic cargo seal
- Keypad personnel authentication
- Automated Collision
- Out of route mapping system or Alert
- In-Vehicle mounted computers
- Remote Vehicle disabling
- Cell phone or paging system
- Reinforced Containers
O Others

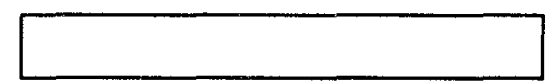

23. Which technology from Question 23 will you say is most effective in reducing risk?

24. When planning a route, is a secondary route proposed in the case of an emergency?

$\begin{array}{ll}\circ & \text { Yes } \\ \circ & \text { No }\end{array}$

If you answered yes to question 25 , how many routes do you associate with origin to destination that is over $\mathbf{2 0 0}$ miles?

25. Rate your organization's preparedness in terms of security breach? ( 1 being not prepared at all, 5 being very prepared)

$\begin{array}{llllll}1 & 02 & 03 & 04 & 05 & 0\end{array}$

26. Rate the level of priority you think the shipping industry in general devotes to security issues? ( 1 being lowest priority, 5 being highest priority) 
$\begin{array}{llllll}1 & 02 & 03 & 04 & 05 & 0\end{array}$

27. Due to the current economic states, have you made significant cuts to your security programs?

o Yes

○ No

If you answered yes to question 28 , what percentage cut have you made?

28. Does your company plan to strengthen current security programs in the near future?

$\circ$ Yes

○ No

29. How do you think security within the shipping industry could best be improved? (Please circle all that apply)

- More staff training

- Stricter controls on illegal immigrants

- safe and secure parking at official truck stops

- improvement to vehicle security systems

- Improvement to facility security

- strict enforcement of regulations by TSA

- Educating other road users

$\circ \quad$ Others

30. Please use this space below to clarify your responses, if suitable. 


\section{APPENDIX B AGENCY SURVEY}

\section{Company Name}

2. Where is your head office located?

3. Which best describes your organization?

- Government

- Private

4. Do you currently have any security awareness training programs for employees/Drivers

- Yes

$\circ$ No

5. Which of the following risk are mostly associated with shipment?

- Theft/ Hijacking

- Sabotage

- Accident

- Vehicle Malfunction

- Leaks

- Terrorism

- Drivers

- Others

6. How is your supply chain protected?

- Careful planning of route

- Use of tracking gadgets 
- standard security inspection policy and procedures

- Use of armed escort

- Following suggested TSA recommendations

- Standard alert protocols

- Standard reporting policy and procedures

- Two Drivers

- Driver(s) take only scheduled rest

- Continuous communication with all parties (e.g., law enforcement, highway emergency service, origin point, destination point, etc.)

- Others

7. Which procedure from Question 20 will you say is most effective in reducing risk?

8. Which of the following technology do you currently use? (Please circle all. that apply)

- RFID's

- Barcodes

- Satellite tracking (GPS)

- Electronic cargo seal

- Keypad personnel authentication

- Automated Collision

- Out of route mapping system or Alert

- In-Vehicle mounted computers

- Remote Vehicle disabling

- Cell phone or paging system

- Reinforced Containers

- Others

9. Which technology from Question 22 will you say is most effective in reducing risk?

10. When planning a route, is a secondary route proposed in the case of an emergency?

- Yes

- No

11. Rate your organization's preparedness in terms of security breach? (1 being not prepared at all, 5 being very prepared)

$\begin{array}{lllllll}1 & 02 & 03 & 04 & 05 & 0\end{array}$ 
12. Due to the current economic states, have you made significant cuts to your security programs?

$\circ$ Yes

- 2 No

13. Does your company plan to strengthen current security programs in the near future?
$\circ$ Yes
- No

14. How do you think security within the logistics industry could best be improved? (Please circle all that apply)

- More staff training

- Stricter controls on illegal immigrants

- safe and secure parking at official truck stops

- improvement to vehicle security systems

- Improvement to facility security

- strict enforcement of regulations by TSA

- Educating other road users

- Others

15. Rate the level of priority you think the logistics industry in general devotes to security issues? ( 1 being lowest priority, 5 being highest priority)

$\begin{array}{llllll}1 & 02 & 03 & 04 & 05 & 0\end{array}$

16. Please use this space below to clarify your responses, if suitable. 


\section{APPENDIX C INLAND WATERWAYS SURVEY}

\section{General Company Information}

\section{Company Name}

2. Location of Head Office

3. How many employees does company have at the moment?

4. Which of the following commodities do you ship on a regular basis? (please Check all that apply)

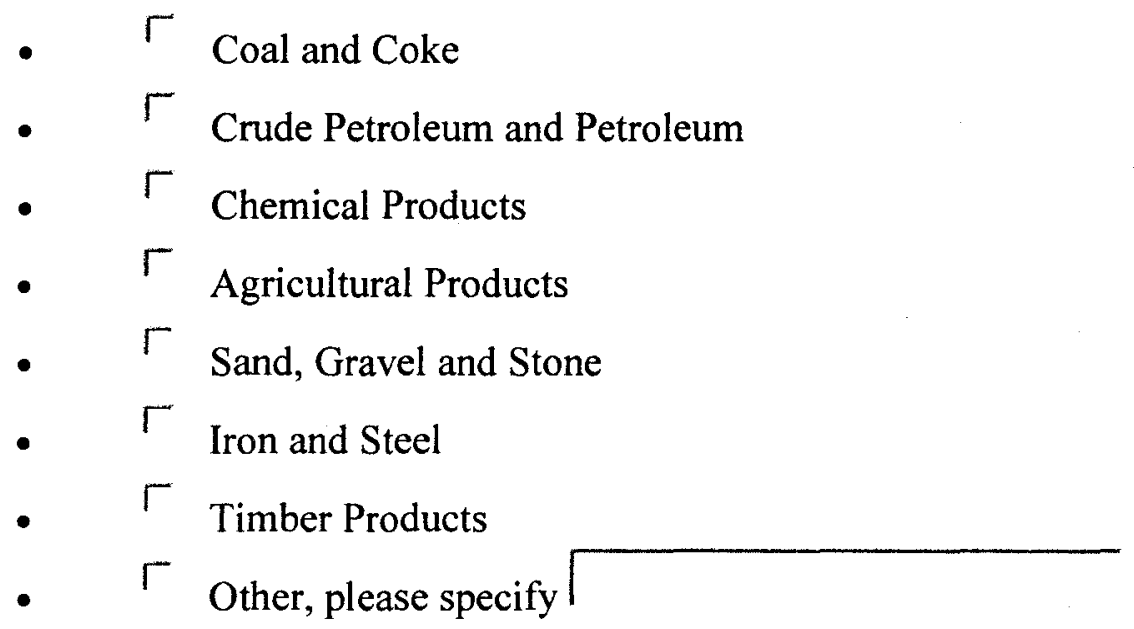

5. What is your total number of outbound shipment per year?

6. What percentage of each transportation mode do you currently use for shipping? (e.g.: Truck - $80 \%$, Railway - 10\% and Water - 10\%) 
Truck

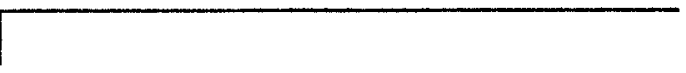

Water

Railway

Pipelines

Air

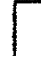

Other(s)

7. On a scale of one to five, one being the lowest, how important is cost in deciding your transportation mode?

8. Do you currently ship via inland waterways? *

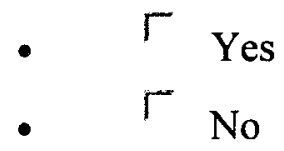

IF YES TO QUESTION 8, PLEASE COMPLETE THIS PAGE. OTHERWISE SKIP TO PAGE 3

9. What are the top three origins and destinations for your products shipped via inland water?

10. What is your weight per shipment via inland waterways? 
11. What are your price saving (by percentage) for shipping on inland waterways versus highway?

12. Have you increased the volume of products shipped via inland waterways as a result of rising gas price?

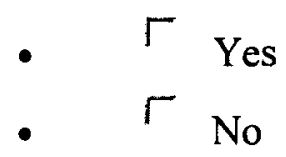

If you answered YES to this question, by what percentage?

13. Cap-and-trade is a policy tool that is being considered to reduce greenhouse gas emissions across the United States. While existing cap-and-trade programs only effect fixed (non-transportation) sources, some policy makers would like to add mobile sources. In a cap-and-trade program, the total amount of greenhouse gasses emitted across the country is capped at a level determined by policy makers. Each emitter is then given a portion of the total emissions allowed. Entities that do not emit their full allocation of greenhouse gases can then trade (or sell) the rights to emit those greenhouse gasses to emitters who have put off more than their allocation. In this way freight carriers who switch some of their cargo from truck to barge can generate significant reductions in emissions and then sell the rights of those emissions to other entities.

If your company had the chance to earn carbon credits for shipping via different modes, would you consider shipping more via inland waterways?

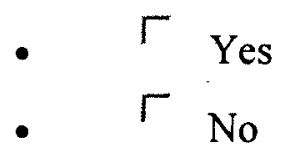

15. Are there any other factors relating to your decision on how to use inland waterways for shipping that we should be aware of?

\section{IF NO TO QUESTION 8, PLEASE COMPLETE THIS PAGE}

16. Are you aware of the cost saving associated for shipping on inland waterways versus highway transportation? 


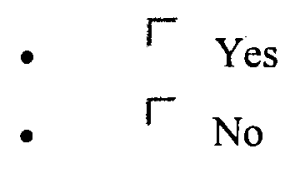

17. For Several years rising gas prices have been touted as having a severe impact on the transportation sector. How expensive would gas have to be for you to consider shipping via the inland waterways?

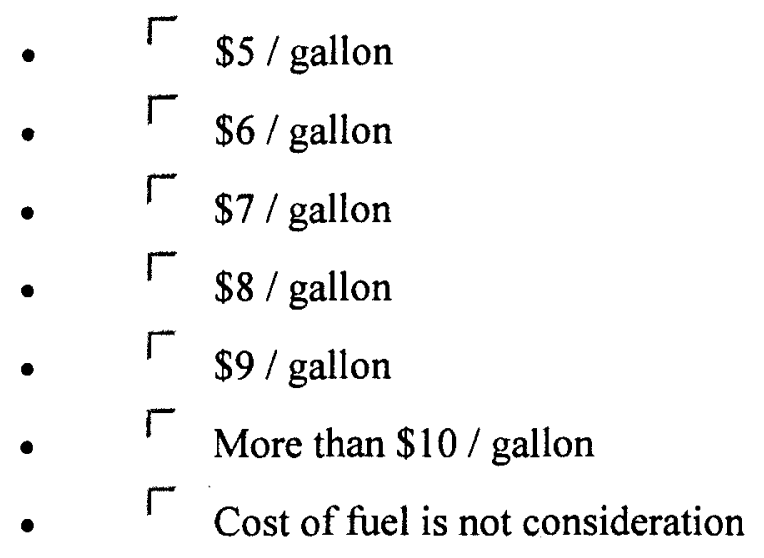

18. Cap-and-trade is a policy tool that is being considered to reduce greenhouse gas emissions across the United States. While existing cap-and-trade programs only effect fixed (non-transportation) sources, some policy makers would like to add mobile sources. In a cap-and-trade program, the total amount of greenhouse gasses emitted across the country is capped at a level determined by policy makers. Each emitter is then given a portion of the total emissions allowed. Entities that do not emit their full allocation of greenhouse gases can then trade (or sell) the rights to emit those greenhouse gasses to emitters who have put off more than their allocation. In this way freight carriers who switch some of their cargo from truck to barge can generate significant reductions in emissions and then sell the rights of those emissions to other entities.

If your company had the chance to earn carbon credits for shipping via different modes, would you consider shipping more via inland waterways?

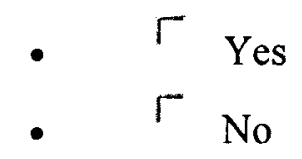

19. Please rank the following factors, 1 being most important, and 6 being least important, in deciding which mode of shipment to use (e.g.: if you think that cost is the second most important factor; give it a rank of "2")

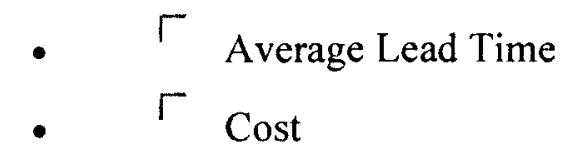


- $\quad \Gamma$ Tracking Capability

- $\Gamma$ Reliability / Predictability of Lead Time

- $\Gamma$ Environmental Factors

- $\Gamma$ Convenience

20. Are there any other factors relating to your decision on not using inland waterways for shipping that we should be aware of? 
APPENDIX D LIST OF ACRONYMS

HazMat

DOT

TSA

FMSCA

HSSM

GPS

IWW

USACE
Hazardous Material

Department of Transportation

Transportation Security Administration

Federal Motor Carrier Safety Administration

Highway Security- Sensitive Materials

Global Positioning System

Inland Waterways

U.S Army Corps of Engineers 


\section{CURRICULUM VITAE}

\section{AYODEJI ABIMBOLA LASISI}

\section{EDUCATION:}

Master of Science, Industrial Engineering

University of Louisville

Projected Graduation Date: December 2011

Bachelor of Science, Mechanical Engineering

University of Kentucky

Graduation: May 2008. 